\title{
The Indian National Association for Study of the Liver (INASL) Consensus on Prevention, Diagnosis and Management of Hepatocellular Carcinoma in India: The Puri Recommendations
}

\author{
Ashish Kumar ${ }^{\star}$, Subrat K. Acharya ${ }^{\dagger}$, Shivaram P. Singh ${ }^{\ddagger}$, Vivek A. Saraswat ${ }^{\S}$, Anil Arora*, Ajay Duseja" \\ Mahesh K. Goenka ", Deepali Jain ${ }^{\#}$, Premashish Kar* ${ }^{\star *}$, Manoj Kumar ${ }^{\dagger \dagger}$, Vinay Kumaran ${ }^{\ddagger \ddagger}$, \\ Kunisshery M. Mohandas ${ }^{\S \S}$, Dipanjan Panda ${ }^{\|\|}$, Shashi B. Paul ${ }^{\top \pi}$, Jeyamani Ramachandran"\#, \\ Hariharan Ramesh ${ }^{\star \star \star}$, Padaki N. Rao ${ }^{\dagger \dagger}$, Samir R. Shah ${ }^{\ddagger \dagger}$, Hanish Sharma ${ }^{\dagger}$, Ragesh B. Thandassery \\ (The INASL Task-Force on Hepatocellular Carcinoma)
}

\begin{abstract}
*Department of Gastroenterology \& Hepatology, Sir Ganga Ram Hospital; †'Department of Gastroenterology, All India Institute of Medical Sciences, Ansari Road, New Delhi 110 029; 'Department of Gastroenterology, SCB Medical College, Cuttack, Odisha; ${ }^{\S}$ Department of Gastroenterology, Sanjay Gandhi Post Graduate Institute of Medical Sciences, Lucknow, Uttar Pradesh; "Department of Hepatology, Postgraduate Institute of Medical Education and Research, Chandigarh; "Department of Gastroenterology, Apollo Gleneagles Hospital, 58, Canal Circular Road, Kolkata, West Bengal 700 054; "Department of Pathology, All India Institute of Medical Sciences; * Department of Medicine, Maulana Azad Medical College, University of Delhi; ${ }^{\dagger \dagger}$ Department of Hepatology, Institute of Liver \& Biliary Sciences; ${ }^{\ddagger \ddagger}$ Department of Surgical Gastroenterology and Liver Transplantation, Sir

Ganga Ram Hospital, New Delhi; $\S^{\S}$ Department of Digestive Diseases, Tata Medical Center, Kolkata, West Bengal 700156; "IIIDepartment of

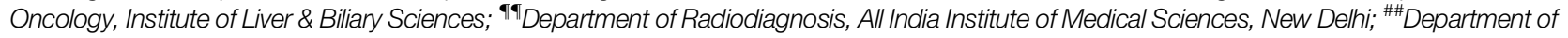
Hepatology, Christian Medical College, Vellore, Tamil Nadu 632 004; **Department of Surgical Gastroenterology, Lakeshore Hospital and Research Center, Cochin, Kerala; ${ }^{\dagger \dagger \dagger}$ Department of Medical Gastroenterology, Asian Institute of Gastroenterology, Somajiguda, Hyderabad; ${ }^{\ddagger \ddagger \ddagger}$ Department of Gastroenterology, Jaslok Hospital and Research Centre, Peddar Road, Mumbai, Maharashtra 400 026, India
\end{abstract}

\begin{abstract}
Hepatocellular carcinoma (HCC) is one of the major causes of morbidity, mortality and healthcare expenditure in patients with chronic liver disease. There are no consensus guidelines on diagnosis and management of HCC in India. The Indian National Association for Study of the Liver (INASL) set up a Task-Force on HCC in 2011, with a mandate to develop consensus guidelines for diagnosis and management of $\mathrm{HCC}$, relevant to disease patterns and clinical practices in India. The Task-Force first identified various contentious issues on various aspects of HCC and these issues were allotted to individual members of the Task-Force who reviewed them in detail. The Task-Force used the Oxford Center for Evidence Based Medicine-Levels of Evidence of 2009 for developing an evidence-based approach. A 2-day round table discussion was held on 9th and 10th February, 2013 at Puri, Odisha, to discuss, debate, and finalize the consensus statements. The members of the Task-Force reviewed and discussed the existing literature at this meeting and formulated the INASL consensus statements for each of the issues. We present here the INASL consensus guidelines (The Puri Recommendations) on prevention, diagnosis and management of HCC in India. （J Clin ExP HePATOL 2014;4:S3-S26)
\end{abstract}

$\mathrm{P}$ rimary liver cancer or hepatocellular carcinoma (HCC) is one of the major causes of mortality among patients with chronic liver disease. The inci-

to become the leading GI cancer. Although there are many consensus guidelines on its management from USA, Europe and Asia, most of these fail to address India specific dence of primary liver cancer is rising in India and is poised issues on management of HCC. Most Indian patients do

Keywords: liver cancer, transplant, RFA, TACE, targeted therapy

Received: 17.6.2013; Accepted: 8.4.2014; Available online 22.5.2014

Address for correspondence: Subrat K. Acharya, Professor, Department of Gastroenterology, All India Institute of Medical Sciences, New Delhi 110029, India. Tel.: +91 11 26594934; fax: +91 1126589130

E-mails: subratacharya2004@yahoo.com; subratacharya@hotmail.com

Abbreviations: AFP: alpha-fetoprotein; AIIMS: All India Institute of Medical Sciences; ASMR: age standardized mortality rate; BCLC: Barcelona-Clinic Liver Cancer; CEUS: contrast enhanced ultrasound; CT: computed tomography; DCP: des-gamma-carboxy prothrombin; DDLT: deceased donor liver transplantation; DE: drug eluting; FNAC: fine needle aspiration cytology; Gd-EOB-DTPA: gadolinium-ethoxybenzyl-diethylenetriamine pentaacetic acid; GPC3: glypican-3; GS: glutamine synthase; HBV: Hepatitis B virus; HCC: hepatocellular carcinoma; HCV: Hepatitis C virus; HSP-70: heat shock protein-70; HVPG: hepatic venous pressure gradient; ICG: indocyanine green; ICMR: Indian Council of Medical Research; INASL: Indian National Association for Study of the Liver; LDLT: living donor liver transplantation; Mabs: monoclonal antibodies; MRI: magnetic resonance imaging; NAFLD: non-alcoholic fatty liver disease; OLT: orthotopic liver transplantation; PAI: percutaneous acetic acid injection; PEI: percutaneous ethanol injection; PET: positron emission tomography; PVT: portal vein thrombosis; RECIST: Response Evaluation Criteria in Solid Tumors; RFA: radio frequency ablation; SVR: sustained viral response; TACE: transarterial chemoembolization; TART: trans-arterial radioisotope therapy; UCSF: University of California San Francisco http://dx.doi.org/10.1016/j.jceh.2014.04.003 
not have access to the expensive treatment of HCC as suggested by these guidelines. In addition, awareness on prevention of HCC, screening of the high risk groups, early diagnosis of HCC and various curative as well as palliative treatment options available for HCC is sub-optimal among the primary and secondary healthcare providers in India.

The Indian National Association for Study of the Liver (INASL) felt a need to develop 'India-specific' consensus guidelines for diagnosis and management of HCC. Therefore, INASL set up a Task-Force on HCC in 2011, with a mandate to develop consensus guidelines on various clinical aspects of HCC, relevant to disease patterns and clinical practices in India. These guidelines are also expected to help in developing a framework for future research on affordable treatment options for HCC in India. The present review summarizes the INASL consensus guidelines on prevention, diagnosis and management of HCC in India.

For the purpose of development of consensus guidelines, the Task-Force identified various contentious issues on various aspects of HCC. The members of the Task-Force reviewed the existing literature and developed consensus statements on each of these issues. A 2-day round table discussion was held on 9th and 10th February, 2013 at Puri, Odisha, to discuss, debate, and finalize the consensus statements. Only those statements that were unanimously approved by the Task-Force members were accepted. These statements were circulated to all the experts and were subsequently presented at the annual conference of the INASL at Hyderabad, in March 2013. The Task-Force adopted the Oxford Center for Evidence Based Medicine-Levels of Evidence of $2009^{1}$ for developing an evidence-based approach. The group assessed the level of existing evidence and accordingly ranked the recommendations [i.e., level of evidence from 1 (highest) to 5 (lowest); grade of recommendation from $\mathrm{A}$ (strongest) to $\mathrm{D}$ (weakest)].

\section{EPIDEMIOLOGY OF HEPATOCELLULAR CARCINOMA (HCC) IN INDIA}

Nationally representative data on epidemiology of HCC is not available. Cancer is not a reportable disease in India and the cancer registries in India are mostly urban. $\mathrm{Na}$ tional cancer registry program of the Indian Council of Medical Research (ICMR) has been recently expanded to include 21 population based and 6 hospital based cancer registries. The last published registry data by ICMR available in the cancer registry website (www.ncrpindia.org) was in 2008 which provides information on various cancers from 2006 to 2008 . $^{2}$ The other source of information was the report published by International Agency for Research on Cancer (WHO). ${ }^{3}$ According to these available data the age adjusted incidence rate of liver cancer in India for men ranges from 0.7 to 7.5 and for women 0.2 to 2.2 per 100,000 persons per year. There is a male preponderance with a male : female ratio of $4: 1$. It was also found that the median age of presentation of liver cancer ranges between 40 and 70 years and with increasing age, the frequency of liver cancer increases.

Dikshit et $\mathrm{al}^{4}$ have published a nationally representative survey on the causes of cancer related mortality in India. The study was conducted by verbal autopsy study in 1.1 million homes representing the whole country. In 2010 at all ages, rates of cancer deaths about 59/100,000 for men and about 52/100,000 for women. Among men, the first 4 causes of mortality included oral, stomach, lung and liver cancer. In 2010 approximately 14,000 deaths would have occurred due to liver cancer with an age standardized mortality rate (ASMR) of 6.8/100,000 population. In women liver cancer was the 8 th common cause of cancer related mortality accounting for 12,000 death in 2010 with an ASMR of 5.1/100,000 population.

The well known risk factors for the development of HCC include cirrhosis of liver of any cause. ${ }^{5}$ About $70 \%-$ $90 \%$ of HCC have been reported globally in cirrhotic livers. ${ }^{6}$ The frequency of HCC in a cirrhotic may vary depending upon underlying etiology of cirrhosis, such as HBV, $\mathrm{HCV}$, alcohol and non-alcoholic fatty liver disease. Paul et $\mathrm{al}^{7}$ had conducted a prospective observational study to assess the HCC incidence among Indian patients with child's A and B cirrhotic without having any HCC at enrollment $(n=194)$ who were followed up for a median duration of 44 months. Each patient had ultrasonography and alpha-fetoprotein (AFP) at 6 month interval and triple phase CT scan annually. During a cumulative 563 person years follow-up 9 cases of HCC (all males) were detected with an annual incidence rate of $1.6 \%$ (95\% CI 0.07-3.0).

None of the case series published from India have provided year wise breakup to assess whether HCC burden is increasing in the tertiary care centers. According to an unpublished data from All India Institute of Medical Sciences (AIIMS) from 1990 to 2012, 1062 consecutive patients with confirmed diagnosis of HCC were registered at the liver clinic at the AIIMS. The data indicates that there is progressive rise in number of HCC cases at AIIMS. Similar trend has also been seen at other tertiary care centers of India which report a burden of HCC as 50-100 cases per year. Yeole had published the population based age adjusted time trends in the incidence of liver cancers in India. ${ }^{8} \mathrm{He}$ reported a significant increase in the liver cancer incidence in Mumbai, Chennai and Bangalore registries.

During the round table discussion at Puri, it was felt by all the experts that there is an urgent need to form an HCC registry under the aegis of INASL, with collaboration from various tertiary care centers of India which manages HCC.

\section{Consensus Statements}

1. The age adjusted incidence rate of bepatocellular carcinoma (HCC) in India for men ranges from 0.7 to 7.5 and for women 0.2 to 2.2 per 100,000 of population per year. (Evidence-2a) 
2. The male:female ratio for HCC in India is 4:1. (Evidence-2a)

3. The age of presentation varies from 40 to 70 years. (Evidence-2a)

4. The age standardized mortality rate for HCC in India for men is 6.8/100,000 and for women is 5.1/100,000. (Evidence-2b)

5. The incidence of HCC in cirrbotics in India is $1.6 \%$ per year. (Evidence-2b)

6. The incidence of HCC is increasing in India. (Evidence1b)

7. There is a need for a multi-centric HCC registry under the aegis of Indian National Association for Study of the Liver (INASL). (Evidence-5, Grade-D)

\section{RISK FACTORS FOR HEPATOCELLULAR CARCINOMA (HCC) IN INDIA}

Worldwide, the single largest risk factor in the development of HCC is cirrhosis of any etiology, which is present in $70 \%-90 \%$ of those who have HCC. ${ }^{6,9}$ Following this, chronic HBV infection, chronic HCV infection, alcohol consumption, and aflatoxin exposure are important risk factors for HCC development. ${ }^{10}$ Less common causes include non-alcoholic fatty liver disease (NAFLD), hereditary hemochromatosis, alpha-1-antitrypsin deficiency, autoimmune hepatitis, some porphyrias, Wilson's disease, smoking and tobacco use. ${ }^{5}$ The distribution of these risk factors among patients with HCC is highly variable, depending on geographic region and race or ethnic group. Diabetes mellitus is also known to be associated with elevated risks of both HCC incidence and mortality. ${ }^{1-13}$ Indian studies have also corroborated these findings and cirrhosis of liver, HBV infection, HCV infection, alcohol consumption, and aflatoxin exposure have been found to be the most important risk factors for HCC development. ${ }^{714-26}$ In addition to these, NAFLD is now increasingly being recognized from India as a cause of HCC. ${ }^{27}$ Diabetes, in addition to being a risk factor of HCC in India, has also been found to be associated with more advanced HCC and poorer outcome. ${ }^{24,28,29}$ In a case-control study, Asim et al observed a positive correlation between age, $\mathrm{HBV}$ and $\mathrm{HCV}$ infection, smoking habit of $>20$ packs/year, alcohol consumption of $>100 \mathrm{~g} /$ day and risk of liver cancer. ${ }^{30}$

Among the various etiological factors being implicated in the cause of HCC, one of the most important cause, howev$\mathrm{er}$, is HBV infection. ${ }^{31,32}$ Insertional mutagenesis, transactivation by truncated $\mathrm{X}$ or $\mathrm{preS} 2 / \mathrm{S}$ regions, and activation of growth regulatory genes or oncogenes have all been suggested as possible mechanisms for this carcinogenesis. ${ }^{33}$ HBV genotype D was the predominant genotype associated with HCC cases seen in India. ${ }^{34}$ In a study on methylation profiling of tumor suppressor genes and oncogenes in hepatitis virus-related HCC from north India the involvement of CDKN2B, SOCS1, CDH1, GSTP1, and MYC in patho- genesis of HCC was shown implicating altered DNA methylation in the molecular pathogenesis of hepatitis virus-related HCC. ${ }^{35}$ In another study it was also found that shorter telomeres are present in telomerase-positive HCC cases. However, no correlation was found between telomerase activity and telomere length with respect to the viral status in HCC. ${ }^{36}$ Although it may be difficult now to predict which HBV infected patient will develop HCC, but with the ready availability of $\mathrm{HBV}$ genotypic variant analysis and genome-wide association studies in the future, the combination of genetic and non-genetic factors may promise a more personalized approach to predicting HCC in chronically HBV-infected patients. ${ }^{37}$ Like HBV, HCV can also cause HCC by various pathogenetic mechanisms. ${ }^{38}$

Investigating for genetic risk factors for HCC in India, Asim et al found that the variants in low penetrance genes of Glutathione-S-transferase such as GSTM1 and GSTT1 are associated with an increased liver cancer risk. ${ }^{30}$ Glutathione-S-transferase and mEPHX variants shared a positive association with viral-related HCC risk in a study from North India. ${ }^{39}$ Katiyar et al found a very low frequency of p53 mutations in HCC patients of India. ${ }^{40}$ Another study from South India indicated that chromosomal alterations and the genetic variations of p53 and XRCC1 might contribute to inter-individual susceptibility to $\mathrm{HCC}^{41}{ }^{41}$ Positive association of XRCC1 genotypes and risk of hepatitis virus-related HCC has been confirmed by Kiran et al. ${ }^{42}$ The same group later found that 113Tyr-139Arg and 113His-139His haplotypes of mEPHX significantly elevated the risk for HCC by 1.4- and 1.5-folds; however, Arg-His-Arg haplotype of XRCC1 did not enhance the risk for HCC. ${ }^{43}$ Because of these discrepant and isolated reports on genetic risk factors for HCC it was concluded at the Puri meeting that currently data is insufficient to implicate any genetic risk factor for HCC in India.

\section{Consensus Statements}

8. Cirrhosis of liver, chronic Hepatitis B virus (HBV) infection, chronic Hepatitis C virus (HCV) infection, alcohol consumption, and aflatoxin exposure are the most important risk factors for HCC development. (Evidence-1a)

9. Other important risk factors are: Diabetes mellitus, non-alcoholic fatty liver disease (NAFLD), smoking and tobacco use. (Evidence-1a)

10. Currently data is insufficient to implicate any genetic risk factor for HCC in India. (Evidence-3b)

\section{PREVENTION OF HEPATOCELLULAR CARCINOMA (HCC) IN INDIA}

Prevention of cancer seems to be the most cost-effective strategy in the war against cancer. In the context of HCC, most HCCs are amenable to prevention. Primary prevention of HCC aims at reducing exposure to various carcinogenic hepatotoxins (initiating agents to induce persistent 


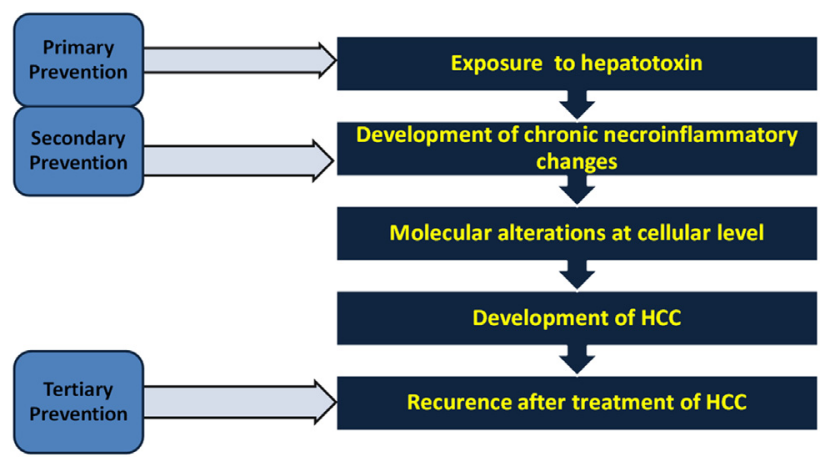

Figure 1 Prevention of HCC: stages and opportunities for intervention.

or chronic liver injury). Secondary prevention of HCC aims at treating the chronic necro-inflammatory state of liver produced by the carcinogenic hepatotoxin (control or remission of ongoing liver injury). Tertiary prevention aims at prevention of recurrence of HCC after initial successful curative treatment (Figure 1).

Ideally, all the three strategies of prevention are necessary for effective control of HCC in a region. However, primary prevention strategies may be better suited for India, because secondary preventive strategies may be too expensive and not very cost-effective. ${ }^{44}$ HCC related to HBV can be primarily prevented by vaccination. Nationwide vaccination of infants in Taiwan reduced the incidence of HCC in children aged 6-9 years from 0.52 per 100,000 for those born between 1974 and 1984 to $0 \cdot 13$ for those born between 1984 and $1986 .{ }^{45}$ Hence, hepatitis B vaccination is strongly recommended to all newborns. HBV vaccination is also recommended to the high risk groups likely to contract HBV infection, such as, healthcare workers, patients with chronic non-communicable disease that require frequent visits to hospitals, etc (Table 1). In healthcare settings, universal precautions to avoid transmission of blood borne viruses should be adopted. Testing of blood and blood products for HBV and HCV is mandatory and must be followed with utmost care. Besides hepatotropic viruses, obesity, NAFLD and alcohol use are important risk factors for HCC, and therefore, healthy life-style should be encouraged including prevention of obesity and alcohol abuse. Metabolic conditions,

\section{Table 1 High Risk Groups Needing Hepatitis B Vaccination.}

People with high-risk sexual behavior.
Partners and household contacts of infected patients.
Intravenous drug users.
People who frequently require blood or blood products.
Recipients of solid organ transplantation.
People at occupational risk of hepatitis B virus. infection, including
healthcare workers.
Kidney dialysis patients and those in early renal failure.
Inmates of a correctional facility.
Staff and clients of institutions for the developmentally disabled.
Patients with chronic ailments who require repeated admissions.

such as diabetes and NAFLD should be appropriately treated and monitored for adequate control of liver injury in such patients.

Among the secondary preventive strategies, effective therapy for viral hepatitis is the most important control strategy. There is strong evidence that antiviral therapy that controls HBV infection in HBsAg-positive patients and that eradicates HCV in patients with viremia substantially reduces but does not eliminate the risk of HCC in patients with viral hepatitis. ${ }^{5}$ In one large Chinese study, patients with chronic HBV infection who also had cirrhosis or advanced fibrosis were randomly assigned to receive $100 \mathrm{mg}$ of lamivudine per day or placebo for up to 5 years; the incidence of HCC was significantly reduced in the lamivudine group as compared with the placebo group (3.9\% versus 7.4\%; hazard ratio, $0.49 ; P=0.047) .{ }^{46}$ In patients with $\mathrm{HBV}$ cirrhosis with high viral load there is evidence that antiviral therapy helps in preventing HCC development and should be recommended. In patients with HBV cirrhosis with low viral load antiviral therapy can be given, however, currently data is not strong in its role in HCC prevention. The long-term studies of lamivudine (and adefovir) show a consistent reduction in the development of liver cancers in patients with, and without, cirrhosis. ${ }^{47}$ However, this beneficial effect is blunted by the development of resistance. The effects of the newer nucleoside/ nucleotide analogs, with higher potency and minimal risk of resistance development, are, as yet, unknown. ${ }^{47}$

In one mathematical simulation model it was found that the probability of developing HCC increases approximately linearly with duration of $\mathrm{HCV}$ infection at the rate of 2.4 incident cases per thousand HCV-infected person years. ${ }^{48}$ This indicates that the sooner viral replication can be suppressed through antiviral therapy, the greater the chance of prevention of development of HCC. The results of one randomized, controlled study and several non-randomized studies involving patients who were infected with HCV but did not have cirrhosis indicated that among those treated with interferonbased therapy who had a sustained viral response (SVR), the risk of HCC was reduced by $57 \%-75 \% .{ }^{49,50}$ Another study showed that among patients with HCV infection who did have cirrhosis and did not have a sustained response to antiviral therapy, the risk of HCC was not significantly reduced with maintenance interferon therapy. ${ }^{5,51}$ In a meta-analysis of 30 studies it was found that among HCV-infected persons at any stage of fibrosis, SVR was associated with reduced risk for HCC (relative risk for all persons, 0.24 [95\% CI, $0.18-0.31]) .{ }^{52}$ Thus it was concluded in the meeting that antiviral therapies aimed at maintaining HBV suppression in patients with chronic hepatitis B and achieving SVR in patients with chronic hepatitis C should be recommended to all those who are candidates for antiviral therapy, since these measures have been 
shown to prevent progression to cirrhosis, and HCC development.

\section{Consensus Statements}

11. Hepatitis $B$ vaccination is recommended to all newborns and bigh risk groups (Table 1). (Evidence-1b, Grade-A)

12. Universal precautions to avoid transmission of blood borne viruses in healthcare settings should be adopted. (Evidence-1b, Grade-A)

13. Testing of blood and blood products for $\mathrm{HBV}$ and $\mathrm{HCV}$ is mandatory and must be followed. (Evidence-1b, Grade-A)

14. Healthy life-style should be encouraged including prevention of obesity and alcohol abuse. (Evidence-2b, Grade-B)

15. Encourage control of metabolic conditions, such as diabetes and NAFLD. (Evidence-2b, Grade-B)

16. Antiviral therapies aimed at maintaining HBV suppression in patients with chronic hepatitis $B$ and achieving sustained viral response in patients with chronic hepatitis $C$ should be recommended to all those who are candidates for antiviral therapy, because these measures have succeeded in preventing progression to cirrbosis, and HCC development. (Evidence-1a, Grade-A)

17. In patients with HBV cirrhosis with high viral load there is evidence that antiviral therapy helps in preventing HCC development and is recommended. (Evidence-1b, Grade-A)

18. In patients with HBV cirrbosis with low viral load antiviral therapy can be given, however, currently data is not strong in its role in HCC prevention. (Evidence-3b, Grade-C)

\section{ROLE OF SURVEILLANCE IN HEPATOCELLULAR CARCINOMA (HCC) PREVENTION}

Early detection by surveillance is the only way to diagnose HCC when curative treatments are feasible in at least 50\%$70 \%$ of these early detected cases. ${ }^{53}$ HCCs detected when symptomatic are associated with a poor prognosis and ones detected on surveillance fare as well as incidentally found ones. ${ }^{54}$ The decision to begin surveillance depends on the degree of risk of HCC for the individual and the extent to which he or she would be treated if diagnosed with the malignant disease. ${ }^{55}$ Level of awareness and attitude of physicians managing CLD patients is a major factor in surveillance of HCC. It is suggested that for HCC surveillance to be effective, several steps need to be enacted. ${ }^{56}$ These include (1) identification of high risk patients who are appropriate for surveillance (HBV and HCV with advanced fibrosis/cirrhosis), (2) availability and accessibility of HCC surveillance to patients at risk in appropriate healthcare settings, (3) recommendation of the intervention by healthcare providers, (4) acceptance of HCC surveillance by patients, (5) adherence to surveillance, recall and follow-up at the recommended intervals, the benefits of therapy, (6) availability of appropriate diagnostic test follow-up for abnormal surveillance, and (7) availability of efficacious curative or palliative treatment once HCC is diagnosed. ${ }^{56}$

Ideally, reduction of disease-specific mortality should be the aim of any cancer surveillance. ${ }^{57}$ In a randomized controlled trial on surveillance, done in China on 18,816 patients with hepatitis B, twice-yearly ultrasonography and measurement of serum AFP concentration was compared with no surveillance. ${ }^{58}$ Despite suboptimal adherence to surveillance $(<60 \%)$, survival of screened participants was $66 \%$ at 1 year, $53 \%$ at 3 years, and $46 \%$ at 5 years versus $31 \%, 7 \%$, and $0 \%$, respectively, in similar patients who were not subjected to surveillance. This study included both cirrhotics and chronic carriers and reported results variably in different publications, making the recent Cochrane database review conclude that there is no evidence favoring surveillance for HC in chronic HBV carriers. ${ }^{59}$ Nevertheless, many population based and clinic based retrospective cohort studies in cirrhotics have found significantly better survival in those whose tumors were asymptomatic but detected on surveillance. ${ }^{60-65}$ These studies are not free from lead time bias (better survival due to anticipated diagnosis of HCC) and length bias (surveillance picking up slow growing tumors) since they are uncontrolled. But when corrected for lead time bias, there was still significant improvement in survival. ${ }^{64,65}$ In view of this evidence that surveillance results in stage migration of HCC, it may be unethical to conduct RCTs in this regard.

Various cost-effectiveness models have suggested that surveillance may be cost-effective and that efficacy is dictated by incidence of HCC. ${ }^{66,67}$ Incidence is the key parameter which determines the cost-effectiveness of screening. Different authors have found different levels of HCC incidence $>1.5 \%$ per year ${ }^{66} 1.4 \%$ year $^{67}$ any level ${ }^{68}$ to be cost-effective with AFP and USG. A systematic review of cost-effectiveness, ${ }^{69}$ analyzing 5 models and 2 studies, found 6 monthly USG with or without AFP to be costeffective. In Asia-Pacific region, where HBV related HCC predominates, it is suggested that HCC surveillance could be effective at reducing disease-specific mortality with acceptable cost-effectiveness among selected patient groups, provided it is a well-organized program. ${ }^{70}$

The Task-Force members concluded that since HCC surveillance can detect early tumors that are potentially amenable to treatment, hence, all patients at risk of developing HCC and who are eligible for HCC therapy are candidates for regular HCC surveillance in India. The treating physician is responsible for the execution of surveillance plan. Involving a nurse educator and improving surveillance with pre-scheduled USG 6 monthly, is recommended by the Task-Force members, to avoid high risk 
patients missing out the benefit of an early diagnosis of HCC.

\section{Consensus Statements}

19. HCC surveillance can detect early tumors that are potentially amenable to treatment, hence, all patients at risk of developing HCC and who are eligible for HCC therapy are candidates for regular HCC surveillance. (Evidence$1 b$, Grade-A)

20. Level of awareness and attitude of physicians managing patients of chronic liver disease (CLD) is a major factor in surveillance of HCC; there is a need for greater healthcare provider awareness and utilization of nurse coordinators to improve delivery of HCC surveillance. (Evidence-2b, Grade-B)

\section{CANDIDATES AND MODALITIES FOR HEPATOCELLULAR CARCINOMA (HCC) SURVEILLANCE}

The groups of patients in whom surveillance is recommended includes cirrhotics of any etiology who are eligible for effective treatment if diagnosed with HCC; patients with chronic HBV infection, age above 40 years, chronic HBV infection with family history of HCC; and patients with $\mathrm{HCV}$ infection with advanced fibrosis. ${ }^{5,53,55}$ Individuals with highly impaired liver function (Child-Pugh class C) should be assessed for liver transplantation. If liver transplantation cannot be offered surveillance is of no benefit because diagnosis will not be followed by effective treatment. Similarly, if liver function deteriorates leading to decompensation and there is no transplantation option, the surveillance is unlikely to be beneficial. ${ }^{55}$ Surveillance is not recommended for patients with NASH or NAFLD without cirrhosis, since HCC is rare in this group. ${ }^{71}$

Ultrasonography is the most commonly used surveillance test which scores over any other radiological test in view of its non-invasive nature, lack of radiation, and less expensive with wide availability. Though it has been found to be very sensitive in detecting asymptomatic tumors in the context of surveillance (94\%), the sensitivity for detecting early-stage tumors is lower (63\%) as shown in a recent meta-analysis ${ }^{72}$ but is currently the best surveillance tool for early-stage HCC among patients with cirrhosis. Performing ultrasound every 6 months instead of annually significantly improves sensitivity for early HCC to $70 \%{ }^{72}$ However the performance of USG as a surveillance test depends on the experience of the examiner. Based on tumor doubling time, USG screening 6 monthly is a reasonable strategy. ${ }^{73}$ A 3-month interval increases detection of small nodules $<10 \mathrm{~mm}$ but not more HCCs or lesions $>30 \mathrm{~mm}^{74}$; and, twice-yearly screening has better results than annual as proved by a very recent Korean study ${ }^{75}$ and a multicentre Italian study. ${ }^{65}$
Serum AFP is the most widely tested biomarker in HCC. Unfortunately, even with the most efficient cutoff $(10-20 \mu \mathrm{g} / \mathrm{L})$, diagnostic sensitivity is around $60 \%{ }^{55,76-78}$ It does not perform well as a surveillance test because fluctuating levels may occur in any chronic $\mathrm{HBV}, \mathrm{HCV}$ not necessarily due to HCC formation. ${ }^{79}$ If elevated, is helpful to define patients at risk. ${ }^{80}$ Cholangiocarcinoma, another common hepatobiliary tumor is also associated with elevated AFP. ${ }^{81}$ The lack of efficacy of biomarkers in surveillance was shown when evaluated prospectively as a part of HALT C trial. AFP and/or des-gamma-carboxy prothrombin (DCP) at and 12 months prior to a diagnosis of HCC had low sensitivity. ${ }^{78}$ Moreover, early tumors for which surveillance is advocated may not produce AFP elevations. A recent metaanalysis demonstrated that at any cut off, addition of AFP to USG does not provide any advantage in detecting early $\mathrm{HCCs}^{72}$ with only non-significant increase in pooled sensitivity from $63 \%$ to $69 \%$. Similar to AFP, other tumor markers, such as DCP or AFP fractions, do not have better accuracy. ${ }^{55,77,78}$

One study from India highlighted the importance of symptomatology of weight loss, abdominal pain or anorexia as markers for HCC in patients with cirrhosis. In the study AFP was not found to be a useful screening test. $^{82}$

\section{Consensus Statements}

21. Following patients should be subjected to surveillance for HCC:

- Patients with cirrhosis

- Child's A and B cirrbotic patients of any etiology

- Child's C cirrbotic patients of any etiology who are listed for liver transplantation

- Patients without cirrhosis

- Patients with chronic hepatitis B: males $>40$ years and females $>50$ years

- Patients with chronic HBV infection of any age with family history of HCC

- Chronic HCV with advanced fibrosis. (Evidence-1a, Grade-A)

22. Six-montbly ultrasound abdomen by experienced personnel is the recommended surveillance test. (Evidence-1a, Grade-A)

23. Serum alfa-fetoprotein has no additive role in surveillance. (Evidence-1a, Grade-A)

\section{DIAGNOSIS OF HEPATOCELLULAR CARCINOMA (HCC)}

Nodules $1 \mathrm{~cm}$ or smaller are diagnosed infrequently as HCC and are almost impossible to diagnose confidently by available techniques (biopsy could miss the target and the diagnostic hypervascular profile is not in place at this stage). ${ }^{55}$ Hence it is recommended that nodules 
of size $<1 \mathrm{~cm}$ should be subjected to a three-monthly follow-up using the same technique which detected the nodule, for two successive follow-ups, to monitor for any enlargement in size. Nodules $<1 \mathrm{~cm}$ may also be evaluated for HCC with gadolinium-ethoxybenzyldiethylenetriamine pentaacetic acid (Gd-EOB-DTPA)enhanced magnetic resonance imaging (MRI) scan and/ or a Sonazoid contrast enhanced ultrasound if available. Gd-EOB-DTPA (gadoxetate sodium) is a new hepatocyte-specific contrast agent for MRI. ${ }^{83}$ This contrast agent is taken up by hepatocytes and excreted from the kidney and from the liver through the bile duct. As a result, liver parenchyma is intensely enhanced showing definite hyperintensity in the hepatobiliary phase $\geq 20$ min after intravenous injection based on T1weighted images, in addition to the diagnosis based on blood supply. Nodules without liver parenchymal cells, such as liver cancer, are visualized as hypointense. Recently contrast enhanced ultrasound (CEUS) has been found to be a very useful modality in diagnosis of HCC. ${ }^{84}$ The Sonazoid CEUS may be more sensitive than dynamic CT for the detection of intranodular arterial blood flow. ${ }^{83,85}$

If a nodule of size $\geq 1 \mathrm{~cm}$ is detected in the liver a dynamic (tri-phasic or four-phasic) CT or MRI scan should be done at centers equipped with appropriate equipment and expertise. On dynamic (tri-phasic or four-phasic) CT or MRI scan features typical of HCC consists of hypervascularity of the nodule in arterial phase and wash-out in porto-venous phase. ${ }^{86}$ The value of these non-invasive criteria for HCC in cirrhosis has been confirmed prospectively. ${ }^{55,87-89}$ Application of helical computed tomography (CT) using the triple phase technique, along with optimized rapid delivery of contrast material has significantly improved the diagnostic confidence of the radiologist in not only detection and characterization of HCC, but also in defining the extent of the tumor. ${ }^{90,91}$ Non-invasive diagnostic criteria are valid only for investigation of screen-detected lesions in the liver in patients with either cirrhosis or long-lasting chronic HBV or HCV infection who might not have fully developed cirrhosis. In other clinical scenarios, a diagnostic biopsy should be obtained. Nodular lesions which show an imaging pattern atypical for HCC on one of the dynamic scans (CT or MRI) should undergo the other dynamic scan (CT or MRI).

Any liver nodule of size $\geq 1 \mathrm{~cm}$ showing atypical imaging pattern on both dynamic scans (CT and MRI) require histological confirmation for diagnosis of HCC. If histological confirmation is required, image guided biopsy is recommended rather than FNAC. The commonest histological pattern seen is trabecular (65\%) followed by anaplastic (17\%), acinar (12\%) and fibrolamellar (6\%). ${ }^{92}$ Architectural pattern, unpaired arterioles, absence of portal tracts and stromal invasion are characteristic histomorphologic hallmarks of HCC. The precancerous lesions such as high grade dysplastic nodule and early HCC can be distinguished by panel of immunohistochemical markers including glypican-3 (GPC-3), glutamine synthase (GS), and heat shock protein-70 (HSP-70). ${ }^{93}$ Poorly differentiated HCC can be distinguished from metastatic cancer by Hep-Par1, pCEA, CK7 and CK20 antibodies. CD10 immunostaining is useful in discriminating HCC and metastatic carcinoma of the liver and is easily applied on cell blocks as well as FNAC smears. ${ }^{94(\mathrm{p} 10)}$ Prognostically important variants of $\mathrm{HCC}$ can be recognized by tissue diagnosis.

If biopsy is not available, USG-guided FNAC of the liver lesion is a safe, simple, cost-effective and probably accurate method for cytological diagnosis of hepatic diffuse, focal/ nodular and cystic lesions with good sensitivity and specificity. ${ }^{95}$ Hepatocytic morphology, trabecular/pseudoacinar pattern, transgressing vessels, peripheral sinusoidal wrapping are characteristic cytomorphologic hallmarks of HCC on FNAC.

The importance of the onco-fetal glycoprotein antigen AFP as an HCC tumor marker for diagnosis of HCC is well documented, ${ }^{96}$ however the accuracy is low at lower cut-off levels. In many cases, when AFP levels ranges between 100 and $600 \mathrm{ng} / \mathrm{ml}$ the diagnostic accuracy of AFP to differentiate between cirrhosis and malignancy is poor. ${ }^{97}$ The etiology of HCC may also determine AFP positivity. Murugavel et $\mathrm{al}^{98}$ found that in HBV and HCV coinfected HCC cases, the AFP positivity was $85.7 \%$. In HBV alone-associated HCC, the positivity was $62.9 \%$, and $54.5 \%$ of aflatoxin B1 positive HCC cases showed AFP positivity. In HBV and $\mathrm{HCV}$ negative $\mathrm{HCC}$ cases, the positivity was $20.5 \%$, and in HCV-associated HCC it was $17.6 \%$. Thus the overall positivity pattern of AFP in HCC does indicate that higher levels of AFP are observed with hepatitis virus positivity, especially with HBV.

PET scan has limited role in diagnosis of HCC. Overall, the FDG-PET sensitivity in detecting HCC is lower (50\%$70 \%$ ) than other liver tumors and the tumor FDG uptake is influenced by cellular differentiation with the lowest performance in well-differentiated HCC. ${ }^{99,100}$

\section{Consensus Statements}

24. If a nodule of size $<1 \mathrm{~cm}$ is detected in the liver, a threemonthly follow-up is recommended using the same technique which detected the nodule, for two successive follow-ups, to monitor for any enlargement in size. (Evidence-2b, Grade-B)

25. Nodules <1 cm may also be evaluated for HCC with gadolinium-ethoxybenzyl-diethylenetriamine pentaacetic acid (Gd-EOB-DTPA)-enhanced magnetic resonance imaging (MRI) scan and/or a Sonazoid contrast enhanced ultrasound if available. (Evidence-3b, Grade-C)

26. If a nodule of size $\geq 1 \mathrm{~cm}$ is detected in the liver a dynamic (tri-phasic or four-phasic) computed tomography (CT) scan or MRI scan should be done at centers equipped 
with appropriate equipment and expertise. (Evidence-1a, Grade-A)

27. On dynamic (tri-phasic or four-phasic) CT or MRI scan, features typical of HCC are characterized by hypervascularity of the nodule in arterial phase and washout in porto-venous phase. (Evidence-1a, Grade-A)

28. If on these scans the features are typical of HCC in the setting of chronic liver disease then biopsy is not necessary for confirmation of diagnosis. (Evidence-1a, Grade-A)

29. Nodular lesions which show an imaging pattern atypical for HCC on one of the dynamic scans (CT or MRI) should undergo the other dynamic scan (CT or MRI). (Evidence-3b, Grade-C)

30. Any liver nodule of size $\geq 1 \mathrm{~cm}$ showing atypical imaging pattern on both dynamic scans (CT and MRI) require histological confirmation for diagnosis of HCC. (Evidence-3b, Grade-C)

31. If histological confirmation is required, image guided biopsy is recommended rather than fine needle aspiration cytology (FNAC). (Evidence-5, Grade-D)

32. Positron emission tomography (PET) scan has limited role in diagnosis of HCC. (Evidence-3b, Grade-C)

\section{STAGING AND OF HEPATOCELLULAR CARCINOMA (HCC) AND TREATMENT ALLOCATION}

There are several potentially curative or palliative approaches to the treatment of HCC, and the choice of treatment is driven by the cancer stage. ${ }^{5}$ Numerous staging systems for HCC have been developed, and they have been validated to varying degrees. To assess the prognosis of all HCC patients, the best staging system should take into account tumor stage, liver function, and physical status. ${ }^{101}$ In addition, the prognosis should be modified according to the treatment. There is no worldwide consensus about the use of any HCC staging system for all HCC patients, and the systems vary significantly by country. The TNM and Okuda staging systems are most commonly used internationally. The Barcelona-Clinic Liver Cancer (BCLC) and CLIP staging systems are used most frequently in Europe, whereas the JIS system has been accepted as a standard in Japan. ${ }^{101}$

The BCLC staging has been widely used as the standard means of assessing the prognosis for patients with $\mathrm{HCC}^{5}$ The BCLC classification, which was introduced in $1999^{102}$ and subsequently updated ${ }^{53}$ is the only system that links the prognosis with treatment recommendations (Figure 2). ${ }^{103}$ It is a useful assessment tool that incorporates data on the patient's performance status (constitutional symptoms due to cancer), number and size of nodules (the tumor burden), and liver function as determined by the Child-Pugh classification system. It has been used and validated in different settings and establishes treatment recommendations for various stages of HCC.

Sarma et al compared the ability of 7 different staging systems in predicting survival in an Indian cohort of patients with HCC. One hundred and one patients of HCC were diagnosed and stratified according to 7 different staging systems; along with analysis of independent predictors of survival and their correlation with it. The CLIP, Tokyo score and BCLC staging system showed a significant difference in the probability of survival. All other staging systems failed to show a significant difference in survival. Thus the

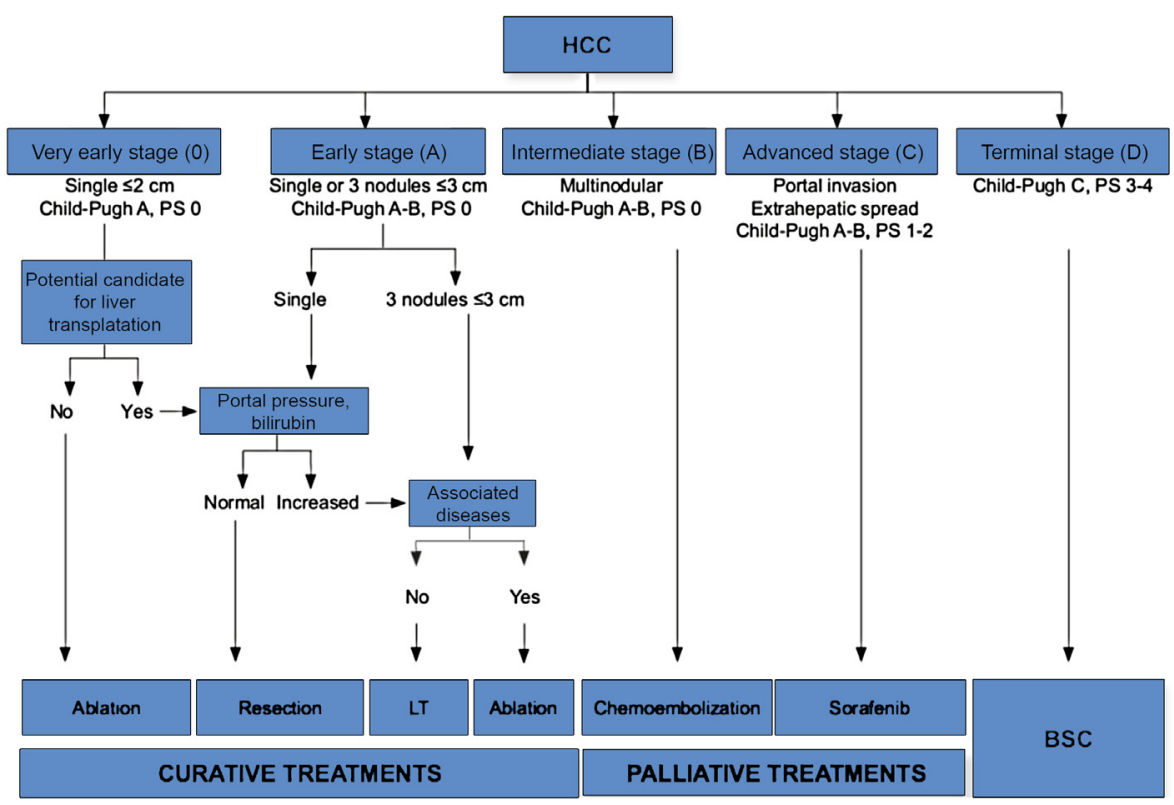

Figure 2 The BCLC staging system. 
authors concluded that the BCLC, CLIP and Tokyo scores are the most useful staging systems in an Indian cohort. ${ }^{104}$

The Task-Force members recommended the BCLC staging system for prognostic prediction and treatment allocation in Indian patients of HCC. BCLC staging system was also found suitable for treatment stage migration; if patients do not fulfill all criteria in each BCLC stage, they may be offered the next most suitable option within the same or next prognostic stage.

In India majority of patients present with advanced disease and up to $13 \%$ have extra-hepatic metastasis at the time of presentation. ${ }^{20,21}$ Extra-hepatic spread precludes any kind of curative treatment; and even chemoembolization is not indicated in such patients. Hence, for accurate staging and appropriate treatment allocation, determination of extra-hepatic spread is essential. Ho et al ${ }^{105}$ suggested that (18)F-FDG PET/CT is useful in the evaluation of HCC metastasis, although its role in the diagnosis of primary HCC is more limited. Dual-tracer PET/CT had an incremental value and complementary advantage when compared with single-tracer imaging in the evaluation of HCC metastasis. High costs and limited availability remain limiting factors for a widespread use of PET/CT in the management of HCC, ${ }^{99}$ hence, extra-hepatic spread may be determined using a CT scan of abdomen plus chest and a bone scan.

\section{Consensus Statements}

33. The Barcelona-Clinic Liver Cancer (BCLC) staging system is recommended for prognostic prediction and treatment allocation. (Evidence-1a, Grade-A)

34. Treatment stage migration: If patients do not fulfill all criteria in each BCLC stage, offer the next most suitable option within the same or next prognostic stage

- BCLC stage A patients failing local ablation: offer transarterial chemoembolization (TACE)

- BCLC stage B patients not responding to at least 2 cycles of TACE: offer Sorafenib. (Evidence-5, Grade-D)

35. For assessment of extra-hepatic spread a CT scan of abdomen plus chest and a bone scan are recommended. (Evidence-4, Grade-C)

36. PET scan may also be used to assess extra-hepatic spread if available. (Evidence-2b, Grade-B)

\section{ROLE OF RESECTION FOR HEPATOCELLULAR CARCINOMA (HCC)}

Liver resection continues to be the mainstay of curative treatment in non-cirrhotic patients and selected cirrhotic patients with small tumors and preserved liver function. ${ }^{106,107}$ In cirrhotic patients with HCC of BCLC stage 0 , resection is the first-line treatment option for solitary tumors $<2 \mathrm{~cm}$, very well-preserved liver function (defined as normal bilirubin with either HVPG $\leq 10 \mathrm{mmHg}$ or a platelet count $\geq 100,000$ ), no vascular invasion/satellites, and with good performance status., ${ }^{5,108,109}$ In center where HVPG is not available, clinically significant portal hypertension should be ruled out by a platelet count $\geq 100,000$, absence of esophageal varices on endoscopy and absence of significant collaterals on abdominal imaging. If indocyanine green (ICG) test is available it can be used to demonstrate good liver function.

Most centers restrict the indication for resection to patients with solitary tumor, because multifocal tumors are associated with high recurrence rates and impaired survival. Although the patients with multifocal tumor, who are not candidates for transplant or do not have access to transplant, need not be viewed as contra-indication to resection or other locoregional therapies which may offer survival benefit. Similarly, tumor size is not a clear-cut limiting factor, but risk of vascular invasion and dissemination increases with diameter. ${ }^{55}$

The 5-year risk of recurrence of HCC after resection is as high as $70 \%$ because the underlying chronic liver disease continues to maintain the risk of development of new HCCs. ${ }^{5}$ While anatomical resections provide improved survival, the choice of non-anatomical versus anatomical resections should be individualized taking into account factors such as cirrhosis and function of the liver remnant. A clear margin of resection is essential in all surgically resected cases. ${ }^{110}$ The overall mortality and morbidity rates with resection were $6.6 \%$ and $44.8 \%$, respectively, from an Indian center, which were comparable with those of most of the recently published Western series. ${ }^{111}$ Re-resection can be carried out in selected patients with recurrence after liver resection provided liver function is stable, and $\mathrm{R} 0$ resection can be achieved.

The current data does not support the use of neoadjuvant or adjuvant therapies in order to improve outcome or prevent recurrence in patients treated with resection. It has been shown that prior resection and salvage liver transplantation for recurrent HCC within UCSF criteria ${ }^{112}$ was feasible and salvage liver transplantation could achieve the same outcome as primary liver transplantation. ${ }^{113}$

\section{Consensus Statements}

37. In non-cirrbotic liver with HCC, resection is the treatment of choice provided an $R O$ resection can be carried out leaving an adequate liver remnant. (Evidence-2b, Grade-B)

38. In cirrhotic patients with HCC of BCLC stage 0 , resection is the first-line treatment option for solitary tumors $<2 \mathrm{~cm}$, very well-preserved liver function (defined as normal bilirubin with either hepatic venous pressure gradient (HVPG) $\leq 10 \mathrm{mmHg}$ or a platelet count $\geq 100,000$ ), no vascular invasion/satellites, and with good performance status. (Evidence-2b, Grade-B)

39. In cirrhotic patients with HCC of BCLC stage A if liver transplantation is not feasible, resection may also be considered for: 
- Cirrhotic patients with multifocal tumors meeting Milan criteria ( $\leq 3$ nodules $\leq 3 \mathrm{~cm}$ ) or

- Cirrhotic patients who have mild portal hypertension.

However, these patients require prospective comparison of resection with loco-regional treatments. (Evidence-4, Grade-C)

40. Neoadjuvant or adjuvant therapies have not proven to improve outcome of patients treated with resection. (Evidence-3b, Grade-C)

41. Salvage transplantation can be done following liver resection in HCC. (Evidence-2b, Grade-B)

\section{ROLE OF LIVER TRANSPLANTATION FOR HEPATOCELLULAR CARCINOMA (HCC)}

Orthotopic liver transplantation (OLT) is theoretically the best treatment available for HCC because it results in complete excision of the cancer, removes remaining liver tissue at risk for the development of de novo cancer, and restores hepatic function. ${ }^{114}$ The best results in liver transplantation are obtained applying the Milan criteria (solitary $\leq 5 \mathrm{~cm}$ or if multiple, a maximum of 3 nodules $\leq 3 \mathrm{~cm}$, without vascular invasion or extra-hepatic spread) and hence liver transplantation is the first treatment choice for these patients. ${ }^{115}$ In 1996 Mazzaferro et $\mathrm{al}^{116}$ reported a 75\% 4year survival rate when using the criteria of only transplanting single HCCs that are less than $5 \mathrm{~cm}$, or multiple HCCs that are less than three in number and each less than $3 \mathrm{~cm}$. The excellent survival rate seen in the Mazzaferro series was replicated in multiple published series. ${ }^{108,114,117,118}$ In a systematic review that included 90 studies, comprising 17,780 patients over 15 years it was shown that the Milan criteria are an independent prognostic factor for outcome after liver transplantation. ${ }^{119}$

The use of primary liver transplantation for small tumors has survival advantage and thus may be more cost-effective. ${ }^{120(\mathrm{p} 7), 121}$ In a Markov-based decision analytic model simulated outcomes, expressed in costs and quality-adjusted life years, for the three treatment strategies (resection, loco-regional therapy followed by salvage liver transplantation, and primary liver transplantation), it was found that in patients with HCC within the Milan Criteria, primary liver transplantation increases survival and quality of life at decreased costs compared with resection or loco-regional therapy followed by salvage liver transplantation. ${ }^{121}$

Some authors have suggested that the Milan criteria may be too restrictive, and that a slight expansion may benefit some patients who are usually excluded. ${ }^{53}$ Among the various expanded criteria, only the University of California San Francisco (UCSF) criteria (one tumor $\leq 6.5 \mathrm{~cm}$, three nodules at most with the largest $\leq 4.5 \mathrm{~cm}$, and total tumor diameter $\leq 8 \mathrm{~cm}$ ) have been prospectively validated with outcome data comparable to those from other retrospective studies. ${ }^{112,122,123}$ In DDLT setting, according to a Markov model ${ }^{124}$ using data from the USA, patients outside the Milan criteria would need to achieve 5 -year survival of $60 \%$ or higher to prevent a substantial decrement to the life-years available to the entire population of candidates for liver transplantation. Thus any decision by a center to expand criteria should take into account the current mortality on the waiting list, and should only be done if a low mortality will not be substantially increased by additional expanded criteria cases. $^{122}$

It seems reasonable and is a common practice, to treat patients on waiting list either with percutaneous ablation or transarterial chemoembolization (TACE) to prevent progression and bridge patients to liver transplantation. ${ }^{53}$ A cost-effective analysis based on Markov model ${ }^{125}$ and another review of cohort studies, ${ }^{126}$ have indicated a benefit of bridging therapies if the waiting time is expected to be longer than 6 months.

In India, living donor liver transplantation (LDLT) using the right or left hemi-liver of a healthy donor is more commonly done than DDLT because of limited availability of deceased-donor organs. LDLT may be offered to patients with small HCC in a cirrhotic liver with similar or better outcomes than DDLT. ${ }^{55,127,128}$ It might be ethically acceptable to offer LDLT to patients with tumor stages beyond the accepted criteria for listing for DDLT, since unlike deceased-donor donation, other listed patients are not adversely affected by this process. ${ }^{122}$ However, the question raises ethical concerns regarding the double equipoise principle, since the risk to the donor might not be acceptable below a certain expected survival threshold for the recipient. The overall donor mortality rate is estimated to be $0.08 \%-0.5 \%$, with mortality being more in the right liver lobe resection group than in the left liver lobe resection group. ${ }^{129}$ It is suggested that any institution using LDLT should provide rigorous safeguards to guarantee full disclosure to donor and recipients and should prevent donor coercion and increased risktaking by the surgical team, when endorsing criteria beyond those accepted for deceased donation. ${ }^{122}$

Patients with advanced HCC exceeding the Milan/ UCSF criteria can be down-staged to fit the criteria using loco-regional therapy. Down-staging of tumors to prevent progression while waiting for an organ or for reduction in size to allow enrollment for transplantation has met with variable success. ${ }^{130}$ Importantly, successfully down-staged patients who are transplanted show excellent tumor-free and overall survival rates, similar to fit-criteria group. ${ }^{131}$

In a study from the Inter-University Consortium of Rome, 158 HCC patients were stratified according to the total tumor diameter $>8 \mathrm{~cm}$ and AFP $>400 \mathrm{ng} / \mathrm{mL}$. At multivariate analysis, both these variables were unique independent risk factors for recurrence, presenting the AFP value $>400 \mathrm{ng} / \mathrm{mL}$ an 8 -fold increased risk for developing 
post-LT HCC recurrence. ${ }^{132}$ Another study from North America has proposed the combination of total tumor volume $<115 \mathrm{~cm}^{3}$ and AFP $<400 \mathrm{ng} / \mathrm{mL}$ for the selection of HCC patients, showing that patients exceeding these cutoffs presented very poor post-LT results (below 50\% at 3 years). ${ }^{133}$ Another meta-analysis suggested that a quantity of AFP $>1000 \mathrm{ng} / \mathrm{mL}$ is associated with poorer outcomes from liver transplantation for HCC. ${ }^{134}$

\section{Consensus Statements}

42. Liver transplantation is indicated for patients of cirrhosis with early-stage HCC (BCLC stage $A)$, who are within the Milan criteria. (Evidence-1a, Grade-A)

43. Compared to other modalities primary liver transplant is a better cost-effective strategy for small HCC with compensated cirrhosis as long as the 1-year survival rate after transplant exceeds $85 \%$ at that center. (Evidence-2b, Grade-B)

44. It is possible to go slightly beyond the Milan criteria (such as University of California San Francisco [UCSF] criteria) without markedly diminishing outcomes. (Evidence-3b, Grade-C)

45. Patients with 2-5 cm (T2) tumors waiting for deceased donor liver transplantation (DDLT) should be offered bridging therapies. (Evidence-2b, Grade-B)

46. Patients beyond the conventional criteria may be offered living donor liver transplantation (LDLT) with a guarded prognosis anticipating a 50\% recurrence rate. (Evidence-2b, Grade-B)

47. Patients beyond the conventional criteria, if LDLT is not an option, should be offered down-staging followed by DDLT. (Evidence-2b, Grade-B)

48. Patients with an alpha-fetoprotein (AFP) level $>400 \mathrm{ng} /$ $\mathrm{ml}$ are at high risk for recurrence after liver transplantation and should be given a guarded prognosis. (Evidence2a, Grade-B)

\section{ROLE OF LOCAL ABLATIVE THERAPIES FOR HEPATOCELLULAR CARCINOMA (HCC)}

Percutaneous ablative therapies are based on injection of chemicals in the tumor (ethanol or acetic acid), or on changes in temperature (radio frequency ablation [RFA], microwave, laser, cryotherapy). ${ }^{53}$ Historically, percutaneous ethanol injection (PEI) was the primary percutaneous treatment for HCC. ${ }^{135}$ With evolution of newer technology, it has now largely been replaced with thermal ablation. ${ }^{136}$ Currently, PEI and RFA are the most widely used percutaneous ablative therapies and are considered the standard of care for patients with BCLC 0-A tumors not suitable for surgery.

PEI is a well-established technique for the treatment of nodular-type HCC that achieves complete necrosis in $90 \%$ of tumors $<2 \mathrm{~cm}, 70 \%$ in those of $2-3 \mathrm{~cm}$ and
$50 \%$ in those between 3 and $5 \mathrm{~cm} \cdot{ }^{115,137-139}$ In patients with Child-Pugh A cirrhosis and early-stage tumors, treatment with PEI has been shown to result in 5-year survival rates of $47 \%-53 \%{ }^{140,141}$ The major limitation of PEI is the high local recurrence rate, which may reach $43 \%$ in lesions exceeding $3 \mathrm{~cm} .{ }^{142}$ Another chemical ablation technique, percutaneous acetic acid injection (PAI), has not offered substantial advantages to PEI except for cost. ${ }^{115,136,143}$

RFA has been the most widely assessed alternative to PEI for local ablation of HCC. The energy generated by RFA induces coagulative necrosis of the tumor producing a safety ring in the peri-tumoral tissue, which might eliminate small-undetected satellites. Considering the reported data, the best results obtained in series of HCC patients treated by RFA provide 5-year survival rates of $40 \%-$ $70 \%,{ }^{144,145}$ and even beyond in highly selected candidates. ${ }^{115,146}$ Consistent with previous studies, RFA requires fewer treatment sessions to achieve comparable anti-tumoral effects. Both PEI and RFA achieve complete necrosis of almost $100 \%$ in tumors smaller than $2 \mathrm{~cm}$, but the effectiveness of PEI falls in larger tumors, in which RFA can still be highly effective. Effectiveness of RFA diminishes in larger lesions, and RFA is not recommended for tumors larger than $5 \mathrm{~cm} .{ }^{55}$ Three independent metaanalyses of RCTs, have confirmed that treatment with RFA offers a survival benefit as compared with PEI in tumors larger than $2 \mathrm{~cm}^{147-149}$ Another recent metaanalysis showed RFA to be superior to PEI in the treatment of small HCC with respect to overall survival, 1, 2, and 3 years survival rates, 1,2 , and 3 cancer-free survival rates, and tumor response. ${ }^{150}$

In expert hands RFA is generally a safe technique, ${ }^{151,152}$ however, side-effects are more frequent after RFA than after other approaches. Major complications are more common with RFA (4\%; 95\% CI, 1.8-6.4\%) than with PEI (2.7\%; 95\% CI, $0.4-5.1 \%) .{ }^{115,149}$ Some tumor locations (subcapsular, vicinity of major blood vessels or biliary tree, near to bowel or heart) should be avoided. ${ }^{153}$ Contrast enhanced US may be used to guide RFA ${ }^{154}$ for better accuracy and precision.

An open question is whether RFA can compete with surgical resection as a first-line treatment for patients with small, solitary HCC. ${ }^{155}$ Two RCTs have been reported with opposite results. Whilst the first one did not identify outcome differences, the second trial suggested a survival advantage for surgical resection. ${ }^{156,157}$

Novel thermal and non-thermal techniques for tumor ablation-including microwave ablation, irreversible electroporation, and light-activated drug therapy-seem to have potential to overcome the limitations of RFA and warrant further clinical investigation. ${ }^{138}$ In a study from India, a new interstitial antenna operating at a frequency of $2.45 \mathrm{GHz}$ for the treatment of HCC using microwave ablation has been found useful. ${ }^{158}$ 


\section{Consensus Statements}

49. Local ablation with radio frequency ablation (RFA) or percutaneous ethanol injection (PEI) is considered the standard of care for patients with BCLC stage 0-A tumors not suitable for surgery. (Evidence-1a, Grade-A)

50. The number and diameter of lesions treated by local ablation should not exceed 5 and $5 \mathrm{~cm}$, respectively. (Evidence-2b, Grade-B)

51. RFA and PEI are having similar efficacy in lesions $\leq 2.0 \mathrm{~cm}$ and RFA provides better local control and overall survival in HCCs $>2 \mathrm{~cm}$. (Evidence-1a, Grade-A)

52. Percutaneous acetic acid injection could be a cost-effective substitute for PEI. (Evidence-5, Grade-D)

\section{ROLE OF TRANS-CATHETER THERAPIES IN HEPATOCELLULAR CARCINOMA (HCC)}

Due to the lack of screening programs in the country, the majority of HCC patients are diagnosed at an advanced stage of the disease, thus curative treatment remains a challenge. Palliative therapy forms the mainstay of treatment for this group of patients. ${ }^{159}$ A variety of percutaneous trans-catheter interventional techniques may be used for loco-regional palliation. ${ }^{160}$ HCC is a hypervascular tumor and derives its blood supply from the hepatic artery. This fact is used by these trans-catheter therapies for delivery of chemotherapeutic drugs, embolic particles, or radioactive materials into arterial vessels nourishing the tumor to induce tumor necrosis and apoptosis. ${ }^{55,138}$

The only trans-catheter option that has shown survival benefit is the transarterial chemoembolisation (TACE). ${ }^{161,162}$ TACE is considered as the primary therapeutic option for unresectable HCC of BCLC stage B. ${ }^{163}$ This procedure combines selective intra-arterial delivery of the chemotherapeutic agents followed by embolic particles in the same feeding artery resulting in temporary embolization. TACE produces ischemic necrosis as well as a sustained cytotoxic effect on the tumor. TACE is commonly associated with a characteristic post embolization syndrome characterized by ischemic hepatitis which may progress to liver failure in those with underlying poor functioning liver reserve, hence patient selection is vital. TACE offers a reasonable palliative therapy for HCC and has been shown by randomized controlled trials to be efficacious in the palliative setting. ${ }^{164,165}$

TACE is indicated in patients of HCC of BCLC stage B (i.e., multinodular tumor with Child-Pugh A or B, performance status 0 , and with no vascular invasion or extrahepatic spread) who have tumor burden $<50 \%$ of liver volume and have adequate bone marrow function. TACE may also be offered to patients with inoperable small tumors (BCLC stage A), which are not amenable for local ablation due to technical limitations. TACE is also used as a neoadjuvant therapy or as a means of downstaging a patient's condition before liver transplantation, but whether these approaches provide a survival benefit is unclear. ${ }^{5,166}$

TACE is contra-indicated in the absence of a proper portal flow, as in portal vein thrombosis, because it may lead to an extensive necrosis of the treated area as all the blood supply to that area will be blocked. There is controversy in the benefits of super selective TACE in the presence of segmental non-tumoral portal vein thrombosis, but the presence of portal vein thrombosis has been constantly correlated to a worse outcome. ${ }^{53,162}$ TACE is also contraindicated in patients with extra-hepatic metastases, PST $>2$, contra-indications to contrast agents, and pregnancy. Performing TACE in patients with deteriorated liver function may lead to severe complications and death due to liver failure. ${ }^{53,167,168}$ HCC having extra-hepatic collateral supply requires additional chemoembolization through the collateral to enhance the efficacy of TACE failing which an alternative loco-regional therapy of percutaneous ablation may be resorted to. ${ }^{169}$

There is no available evidence regarding the choice of chemotherapeutic agent, dosage, dilution and the rate of injection. ${ }^{155}$ Doxorubicin, mitomycin and cisplatin are the common chemotherapeutic drugs used alone or in combination. There is evidence to show some benefit with combination of chemotherapeutic agents however further study is warranted. The optimal re-treatment strategy remains unknown. More intense regimes of repeating TACE every 2 months has been shown to induce liver failure in high proportion of cases. ${ }^{170}$

More than $50 \%$ of patients have an objective response, as shown by extensive tumor necrosis, which translates into improved survival. Two meta-analyses of pooled data from the most relevant randomized controlled trials concluded that TACE improves survival in these patients. ${ }^{171,172}$ The initial tumor size is an independent predictor of survival. ${ }^{173}$ A recent Cochrane meta-analysis has challenged the efficacy of TACE. However, due to numerous biases, the impact of this result has been diminished. ${ }^{174}$

The ideal TACE scheme should allow maximum and sustained intra-tumoral concentration of the chemotherapeutic agent with minimal systemic exposure, along with calibrated tumor vessel obstruction. ${ }^{155}$ TACE-DEB uses drug eluding beads as the chemotherapeutic agent. Embolic microspheres have the ability to sequester chemotherapeutic agents and release them in a controlled mode over a one-week period. This strategy has been shown to increase the local concentration of the drug with negligible systemic toxicity. ${ }^{155,175}$ A randomized phase II study comparing TACE and TACE-DEB reported a significant reduction in liver toxicity and drug-related adverse events for the latter arm, associated with a non-significant trend of better anti-tumoral effect. ${ }^{176}$ Patients with more advanced disease (Child-Pugh B, PST 1, and bilobar or recurrent disease), demonstrated a significantly better local 
response and survival. Improved local response and fewer treatment sessions are required with the use of TACEDEB in comparison to conventional TACE and further evidence is still evolving. ${ }^{177-179}$ The predicted lower side effects with DEB-TACE with less hospitalization have not translated to overall reduction in costs. ${ }^{180}$

Bland trans-arterial embolization (TAE), without the use of chemotherapeutic agents, is also an effective treatment of HCC. A meta-analysis of nine randomized controlled trials confirmed that TACE improves survival; but a meta-analysis of TACE versus TAE alone ( 3 RCTs, 412 patients) demonstrated no survival difference. ${ }^{181}$ However, in another study it was found that compared to TAE, TACE significantly prolonged progression free survival and time to progression, but not overall survival. ${ }^{182}$ Thus though TAE is efficacious but the outcome with TACE is better. Hence bland TAE is not advised currently.

Many patients of HCC have associated portal vein thrombosis, making them unsuitable for TACE, depending upon the level and severity of thrombosis. Such patients can be offered internal radioisotope therapy to prolong their survival and improve the quality of life. ${ }^{183}$ The aim of radioisotope therapy is to deliver the radioisotope to the hepatic tumor, where it must reside for a period sufficient to deliver the scheduled dose of radiation. At the same time the amount delivered to the normal liver parenchyma and other organs should be as low as possible. A variety of radioisotopes, such as lodine-131, Yttrium-90, Rhenium-188, Holmium-166 etc. can be used for this purpose and targeting of the therapeutic agent to the tumor may be achieved by 1) direct intra-tumour implantation of the radioisotope, 2) parenteral injection of radiolabelled antibodies specific to HCC antigens (radioimmunotherapy) or, 3) injecting the radioisotope through the hepatic artery directly into the tumor or trans-arterial radioisotope therapy (TART). ${ }^{183}$ In a multicenter trial from India, TART was found to be a safe, effective, and promising therapeutic option in patients with inoperable HCC. ${ }^{184}$ However, the availability of Rhennium is a constraint here. Due to logistic limitations and radiation exposure, Yttrium-90 microspheres (Y90) microspheres are currently in use. Y90 is delivered according to the tumor burden at the lobar artery level for distribution to hepatic tumors. The procedure precludes mandatory evaluation of the shunt fraction and mesenteric vascular anatomy to prevent radiation induced pneumonitis, gastric ulcers, pancreatitis etc. This may exclude a significant number of patients and also add to the cost. TART has shown comparable efficacy in terms of local response, time to progression and superiority in terms of downstaging tumors when compared to TACE. ${ }^{185,186}$ Due to the availability of an efficacious modality of TACE and the high cost of TART, the current role for TART is limited in India. An important indication of the use of TART is in patients of HCC with portal vein thrombosis, where the use of TACE can result in significant side effects. Such patients can be offered TART to prolong their survival and improve the quality of life (167). Patients with Child-Pugh A disease, regardless of portal vein thrombosis, have derived maximum benefit, whereas those with Child-Pugh B and portal vein thrombosis have had poor outcomes. ${ }^{186}$

\section{Consensus Statements}

53. TACE is indicated in patients of HCC of BCLC stage B (i.e., multinodular tumor with Child-Pugh A or B, performance status 0 , and with no vascular invasion or extra-hepatic spread) who bave tumor burden $<50 \%$ of liver volume and have adequate bone marrow function. (Evidence-1a, Grade-A)

54. TACE may also be considered:

- for patients of $B C L C$ stage $A$, in whom local ablation has technical limitations

- for downsizing patients for resection or transplantation (Evidence-2b, Grade-B)

55. TACE is contra-indicated in patients with:

- Advanced liver disease: Child class C,

- Main portal vein thrombosis (PVT)

- Extra-bepatic metastases

- Hepatofugal blood flow

- Performance status stage $>2 *$

- Contra-indications to contrast agents

- Pregnancy (Evidence-1a, Grade-A)

56. Trans-arterial embolization (TAE) is efficacious but the outcome with TACE is better. Hence bland TAE is not recommended currently. (Evidence-1a, Grade-A)

57. TACE using drug eluting (DE) beads bas comparable local response to lipiodol TACE and has less systemic side effects. Further evidence for long term survival and cost benefit is still emerging. TACE with DE beads may be preferred in select patients. (Evidence-2b, Grade-B)

58. Trans-arterial radioisotope therapy (TART) with Yttrium 90 may be considered in select patients of advanced HCC with portal vein thrombosis and good liver function (Child A). (Evidence-2b, Grade-B)

*Note: Performance Status:

World Health Organization Performance Status stages:

Stage 0: Fully active, normal life, no symptoms.

Stage 1: Minor symptoms, able to do light activity.

Stage 2: Ambulatory and capable of all self-care but unable to carry out any work activities. Up and about more than 50\% of waking hours.

Stage 3: Capable of only limited self-care, confined to bed or chair more than $50 \%$ of waking hours.

Stage 4: Cannot carry on any self-care. Totally confined to bed or chair. 


\section{ROLE OF MEDICAL THERAPY IN HEPATOCELLULAR CARCINOMA (HCC)}

Knowledge of molecular events that govern tumor progression and dissemination has allowed the development of targeted treatments that aim to abrogate these disrupted pathways. Several monoclonal antibodies (Mabs) and small molecules (nibs) are currently being evaluated in clinical trials. The only drug with proven survival benefit is Sorafenib. ${ }^{187,188}$ This agent, which is administered orally, is a multikinase inhibitor that blocks Raf signaling and VEGF, PDGF, and c-Kit. It has antiproliferative and antiangiogenic activity and delays tumor progression. ${ }^{55}$

A randomized controlled double blind trial, ${ }^{187}$ reported a $37 \%$ increase in overall survival (equivalent to a gain of 2-3 months of life), as compared with placebo, in patients with advanced HCC and compensated cirrhosis. Similar findings were replicated in another randomized controlled trial among Asian patients. ${ }^{188}$ However, there were major differences in the etiology of the HCC in the Asian trial and the overall survival in the Sorafenib arm was lower in the Asian trial. Rash on the hands and feet, diarrhea, and fatigue are the most commonly reported side effects of Sorafenib. ${ }^{5}$ Safety data of Sorafenib has been reproduced in a large phase 4 study of more than 3000 patients from 39 countries. ${ }^{189}$ These results have established Sorafenib as the standard of care for HCC of BCLC stage C. ${ }^{83,155,190,191}$ This has also paved the way for evaluation of combination or sequential strategies to improve the effectiveness of Sorafenib as single agent ${ }^{55}$ and many such trials are underway. Pending reports from these studies, the combination of Sorafenib with transplantation or resection, either sequential or concomitant, cannot be recommended currently, outside clinical trials. Sorafenib can be given for residual/recurrent disease after surgery/transplant/TACE/RFA. Presently there is no evidence that combination Sorafenib with other cytotoxic agents or targeted agents or hormonal therapy is superior to Sorafenib alone. In case of progression or intolerance to Sorafenib, best supportive care is preferred or patients should be included in clinical trials.

The use of systemic chemotherapy has not been found to be effective in management of HCC in randomized controlled trials. Two phase II studies from India have evaluated the role of cytotoxic chemotherapy in HCC. Parikh et al found that a regimen containing gemcitabine and cisplatin in patients with advanced HCC was well tolerated in a phase II study. ${ }^{192}$ Subsequently Pande et al reported a partial response rate in $25 \%$, and stable disease in an additional $50 \%$ to three or more cycles of chemotherapy with gemcitabine and cisplatin, with a median overall survival of 7.5 months (95\% confidence interval, 4.5-10.5) and acceptable toxicity profile from their retrospective study of 24 patients of HCC. ${ }^{193}$ Till we have more randomized trials showing distinct benefit, the use of systemic chemo- therapy in management of HCC is not recommended outside of clinical trials. Similarly the use of systemic cytotoxic chemotherapy, immunotherapy, or hormonal therapy (such as tamoxifen, anti-androgens, somatostatin analogs) are not recommended for the clinical management of HCC, either alone or in combination or as adjuvant or neoadjuvant therapies. ${ }^{191}$ Given the current evidence, Sorafenib should be included in the comparator arm.

In a small Indian study treatment of advanced HCC with high dose vitamin $\mathrm{K}$ produced objective response in $17 \%$ patients with improved survival in patients achieving objective response; however, it did not affect the overall survival. ${ }^{194}$ Larger trials showing good response is needed before high dose vitamin $\mathrm{K}$ can be recommended for clinical use.

\section{Consensus Statements}

59. Targeted molecular therapy with Sorafenib is indicated in patients of HCC of BCLC stage C. (Evidence-1b, Grade-A)

60. The combination of Sorafenib with transplantation or resection, either sequential or concomitant, cannot be recommended outside clinical trials, however, Sorafenib can be given for residual/recurrent disease after surgery/transplant/TACE/RFA. (Evidence-3b, Grade-C)

61. There is no evidence that combination Sorafenib with other cytotoxic agents or targeted agents or hormonal therapy is superior to Sorafenib alone. (Evidence-4, Grade-C)

62. In case of progression or intolerance to Sorafenib, best supportive care is preferred or patients should be included in clinical trials. (Evidence-1b, Grade-A)

63. Use of systemic cytotoxic chemotherapy, immunotherapy, or hormonal therapy (such as tamoxifen, anti-androgens, somatostatin analogs) are not recommended for the clinical management of HCC, either alone or in combination or as adjuvant or neoadjuvant therapies. (Evidence-1b, Grade-A)

\section{ROLE OF EXTERNAL BEAM RADIATION THERAPY IN MANAGEMENT OF HEPATOCELLULAR CARCINOMA (HCC)}

Better understanding of partial liver tolerance of radiation therapy and technological advances have improved our ability to deliver tumoricidal doses of radiation safely to HCCs, and have led to a resurgence of interest in curative-intent treatment of HCC using radiation therapy. ${ }^{195}$ Promising clinical data from multiple studies suggest that HCCs are indeed radiosensitive. Sustained local control rates ranging from $71 \%$ to $100 \%$ have been reported following 30-90 Gy delivered over 1-8 weeks. ${ }^{195-197}$ It is suggested that doses greater than 75 Gy results in more durable in-field local control than lower doses. ${ }^{195}$ Three- 
dimensional conformal radiotherapy makes it possible to direct high-dose radiation to HCC with sparing of the surrounding non-tumoral liver parenchyma and represents a promising powerful technique which needs further validation. ${ }^{190}$ Improved understanding of partial liver radiation therapy tolerance and better radiation therapy planning and delivery have advanced the ability to escalate radiation dose to unresectable HCCs without causing undue toxicity. ${ }^{195}$

In an Indian study by Dhir et a ${ }^{198} 27$ patients with HCC were treated by sequential methotrexate $\left(75 \mathrm{mg} / \mathrm{m}^{2}\right)$ and 5 fluorouracil (5-FU) $\left(750 \mathrm{mg} / \mathrm{m}^{2}\right)$ on day 1 followed on days $8-36$ by external beam radiotherapy (total dose $30 \mathrm{cGy}$ ). The overall response to the treatment was $26 \%$. More than a $50 \%$ reduction in serum AFP level was noted in $67 \%$ patients. Seventy-one percent of patients had palliation of pain following therapy. The median survival of responders was 11 months and of non-responders, 2 months. ${ }^{198}$

However, till more trials are available, radiation therapy cannot be recommended for management of HCC outside of clinical trials.

\section{Consensus Statements}

64. External beam radiation therapy is a promising tool in management of some unresectable HCC. (Evidence-2b, Grade-B)

65. Clinical trials using radiation therapy either alone or in combination with other modalities should be undertaken to better evaluate its effectiveness, however, use of radiation therapy cannot be recommended outside of clinical trials. (Evidence-5, Grade-D)

\section{TREATMENT RESPONSE EVALUATION AND FOLLOW-UP IN HEPATOCELLULAR CARCINOMA (HCC)}

The most important parameter for any cancer treatment response evaluation is overall survival. Nonetheless, tumor response and time to progression have been considered pivotal for surrogate assessment of efficacy. HCC tumor response was initially measured according to the Response Evaluation Criteria in Solid Tumors (RECIST) guidelines. ${ }^{199}$ These criteria were designed primarily for evaluation of cytotoxic agents. They did not address measures of antitumor activity other than tumor shrinkage. Most HCC treatments cause tumor necrosis and/or reduce its vascularity. Tumor size shrinkage may not be there in spite of response. Hence, to assess viable tumor contrast uptake in arterial phase has to be assessed using dynamic CT or MRI studies. Consequently, a modification of the RECIST criteria has been adopted. ${ }^{200}$ This proposal is based on the fact that diameter of the target lesions with viable tumor should guide all measurements. Thus the Task-Force recommended that the treatment response evaluation should be done using dynamic CT or MRI studies and modified-RECIST criteria should be used to assess response.

The timing of initial treatment response evaluation should depend on treatment: Following resection, ablation or TACE the initial response evaluation should be done at 4 weeks. The initial response evaluation following liver transplantation should be done at 3 months.

Further follow-up of patients who underwent resection or RFA should consist of the clinical evaluation of liver decompensation and the early detection of recurrence by dynamic CT or MRI studies every 3 months the first 2 years and surveillance every 6 months later on. ${ }^{190}$ Patients with recurrence following radical therapies may still be candidates for curative therapies.

The risk of tumor recurrence after liver transplantation for HCC is $8-20 \% .{ }^{122,201}$ HCC recurrence is usually seen within the first 2 years after liver transplantation, and is associated with a median survival of less than 1 year from the time of diagnosis. ${ }^{202}$ The adoption of posttransplant surveillance criteria has led to the detection of early recurrence, with a possibility of cure with ablation therapies in up to a third of cases. ${ }^{122,203}$ Following the initial response assessment at 3 months, the surveillance for recurrence should be done every 6 months.

The follow-up of patients with more advanced stages of HCC who were treated with TACE or systemic agents (e.g. Sorafenib) should be done every 2 months by clinical evaluation for signs of liver decompensation and for tumor progression by dynamic CT or MRI to guide therapy decisions.

Serum tumor markers (such as AFP levels or desgamma-carboxy prothrombin [DCP]) may be helpful for treatment response evaluation or follow-up when the level was high at diagnosis, and the level decreased after treatment but rises again especially in none or difficult to measure lesions. ${ }^{204-206}$ However tumor markers cannot replace imaging modalities.

\section{Consensus Statements}

66. The treatment response evaluation should be done by dynamic CT or MRI studies using the modified-RECIST (modified-Response Evaluation Criteria in Solid Tumors) criteria. (Evidence-1b, Grade-A)

67. The timing of initial treatment response evaluation should depend on treatment used as follows:

- Resection-4 weeks

- Liver transplantation-3 montbs

- Percutaneous ablation-4 weeks

- TACE-4 weeks (Evidence-2b, Grade-B)

68. The follow-up of patients who underwent curative treatments should consist of clinical evaluation for liver decompensation and the early detection of recurrence by dynamic CT or MRI studies every 3 months for the first 2 years and routine surveillance every 6 months thereafter. (Evidence-1b, Grade-A) 
69. In case of tumor recurrence after curative treatments, reassesses the patient using the BCLC staging system and retreat accordingly. (Evidence-1b, Grade-A)

70. The follow-up of patients who underwent palliative treatments should consist of clinical evaluation for liver decompensation and dynamic CT or MRI for tumor progression every 3 months to guide therapy decisions. (Evidence-1b, Grade-A)

71. Serum tumor markers (such as alpha-fetoprotein levels or des-gamma-carboxy protbrombin [DCP]) may be belpful for treatment response evaluation or follow-up when:

- The level was high at diagnosis, and

- The level decreased after treatment but rises again especially in none or difficult to measure lesions.

However tumor markers cannot replace imaging modalities. (Evidence-3b, Grade-C).

\section{ROLE OF SUPPORTIVE CARE FOR ADVANCED HEPATOCELLULAR CARCINOMA (HCC)}

The prognosis for BCLC stage D patients is dismal, with an expected survival of less than 3 months. ${ }^{103}$ These patients should receive palliative support including management of symptoms, nutrition and psychological support.

Pain in terminal HCC may be difficult to manage. Opioid analgesia should be used for pain management in terminal stage HCC. The opioids that can be safely used in cirrhotic patients with HCC are morphine, hydromorphone, methadone, levorphanol, buprenorphine and fentanyl. ${ }^{207}$ However, a recent systematic review of RCTs of opioids for cancer pain showed fair evidence for the efficacy of transdermal fentanyl and poor evidence for morphine, tramadol, oxycodone, methadone, and codeine. ${ }^{208}$ Radiotherapy can be used to alleviate pain in patients with bone metastasis ${ }^{209}$ and relieve of symptoms from pulmonary $^{210}$ or lymph node metastases. ${ }^{211}$

Nutritional status assessment is important for identifying the risk of deteriorating quality of life or functional status, in patients with HCC. ${ }^{212}$ The current data do not compellingly justify the routine use of parenteral nutrition, enteral nutrition, or oral nutritional supplements in these patients, ${ }^{213}$ however, in individual cases, dietary counseling and artificial nutrition can slow down nutritional deprivation, avoid dehydration and improve the quality of life.

Psychological, social and spiritual factors may exacerbate physical suffering. For instance, depression amplifies pain and other somatic symptoms. ${ }^{214}$ When physical, psychological, and spiritual sources of distress are inseparably intermixed causing "total pain syndrome", a fully integrated clinical approach that addresses the multiple dimensions of suffering is required. ${ }^{215}$ Management of psychosocial and spiritual issues should be a part of the care of terminal HCC patients.
Gastrointestinal hemorrhage in patients with HCC is common and a major contributor to mortality. These patients tend to have a very poor prognosis. There may be a role of transhepatic arterioembolization in the management of gastrointestinal bleed in such patients. ${ }^{216}$

Tumor rupture is another life threatening complication of HCC. On multivariate logistic regression analysis, underlying diseases of hypertension and liver cirrhosis, tumor size $>5 \mathrm{~cm}$, vascular thrombus and extra-hepatic invasion were predictive for spontaneous rupture of $\mathrm{HCC}^{217}$ while serum bilirubin level, shock on hospital admission, and pre-rupture disease state were important prognostic factors to predict survival in the acute phase following rupture. ${ }^{218}$ TAE is effective in controlling bleeding from ruptured HCC in the acute phase. For definitive treatment, staged liver resection after attaining hemostasis is better than 1-stage emergency liver resection. Laparoscopy and laparoscopic ultrasonography may decrease unnecessary exploratory laparotomy, thus increasing the resection rate of previously ruptured HCC. Prolonged survival can be achieved in select patients with definitive treatment. It is still uncertain whether the longterm outcome of liver resection is the same for HCC with and without rupture when patients with the same tumor stage and liver functional state are compared. ${ }^{218}$

Consensus Statements

72. Patients with BCLC stage $D$ have a poor survival and should receive palliative support including management of pain, nutrition and psychological support. (Evidence1b, Grade-A)

73. Opioid analgesia should be used for pain management in terminal stage HCC. (Evidence-1a, Grade-A)

74. Radiotherapy can be used to alleviate pain in patients with bone metastasis and relieve of symptoms from pulmonary or lymph node metastases. (Evidence-3b, Grade-C)

75. Routine artificial nutrition is not justified in patients in the terminal stage HCC, however, in individual cases, dietary counseling and artificial nutrition can slow down nutritional deprivation, avoid debydration and improve the quality of life. (Evidence-3b, Grade-C)

76. Management of psychosocial and spiritual issues should be a part of the care of terminal HCC patients. (Evidence-5, Grade-D)

77. TAE is effective in controlling bleeding from ruptured HCC. (Evidence-2b, Grade-B)

\section{INDIAN NATIONAL ASSOCIATION FOR STUDY OF THE LIVER (INASL)'S ROLE IN ONGOING AND FUTURE RESEARCH ON HEPATOCELLULAR CARCINOMA (HCC) IN INDIA}

Cancer is a rapidly fatal disease. The time taken for any new discovery of therapeutic option in laboratory to its 
clinical application in patients of cancer needs to be as short as possible; only then the newer patients of HCC can hope to live longer than the previous pool of HCC patients. In India, a lot of exciting basic research work in $\mathrm{HCC}$ is already going on ranging from chemoprevention, to genetic aspects to development of newer drugs. For example, studies are on way on the molecular mechanisms involved in the chemoprevention of HCC and have found that dietary supplementation of silymarin can be associated with decreased cell proliferation, increased apoptosis, and activation of detoxification system in rat model of HCC. ${ }^{219}$ In another Indian study, evidence of an increased population of Treg has been found not only in the peripheral blood but also in tumor microenvironment of HCC patients, suggesting association of enhanced Treg activity with poor immune responses to tumor antigens, thus paving way for a future significant role of immunotherapeutic approaches in treatment of HCC. ${ }^{220}$ In another study over expression of endothelial cell marker CD34 has been found in HCC thus suggesting antiangiogenic therapy for these patients. ${ }^{22}$ The oxidation of plasma proteins, especially HSA, has been shown to enhance oxidative stress in HCC patients ${ }^{222}$ suggesting a role for anti-oxidative therapies. A novel propofol-linoleic acid-loaded escheriosomal formulation has been found active against murine $\mathrm{HCC}^{223}$ thus opening a newer therapeutic approach for HCC. These basic research endeavors in India need to be encouraged further and a greater cooperation and crosstalk needs to be established among all basic researchers on HCC so that India leads the way in liver cancer research in the world. INASL can form a platform of cooperation for the basic researchers of HCC in India.

The second major role of INASL is in creating a registry or database of patients of HCC across the country. This database will not only serve to characterize the clinical and etiological profile of HCC in India, it will also help in generating data on temporal trends of epidemiology of HCC in India. It will also be able to highlight the differences in profile of HCC patients in India as compared to other regions of the world and thus help us in focusing our research efforts to the unexplored aspects of HCC specific to India.

The third important role of INASL is in coordinating multi-centric clinical trials on HCC in India. India urgently needs clinical trials on various aspects of HCC which are specific for India. For example, we need trials on cheaper alternatives to Sorafenib which can be afforded by majority of Indian HCC population in whom Sorafenib cannot be used due to prohibitive costs. Similarly, trials on needed on percutaneous ablation therapies which are much cheaper than RFA. We also need to explore the most cost-effective surveillance modality for HCC which can be used in the huge population of chronic liver disease in India.

\section{CONCLUSIONS}

These are the first clinical practice guidelines generated by INASL on the diagnosis and management of HCC in India. These guidelines are evidence based and are aimed at providing the best possible care to the patients of HCC in India according to the current evidence. They will also ensure a uniformity of diagnostic and treatment approaches of HCC in the entire country and will also serve as framework for future research on HCC in India. As more evidence is generated, especially from India, in next 3-4 years, these guidelines will need to be updated and revised.

\section{CONFLICTS OF INTEREST}

The author has none to declare.

\section{REFERENCES}

1. $\mathrm{CEBM}>\mathrm{EBM}$ Tools $>$ Finding the Evidence $>$ Levels of Evidence 2 $>$ Levels of Evidence 1. Available at: http://www.cebm.net/index. aspx?o=1025. Accessed 24.02.13.

2. PBCR Reports 2006-2008... Available at: http://www.ncrpindia. org/Reports/PBCR_2006_2008.aspx. Accessed 24.02.13.

3. Cancer Incidence in Five Continents. Available at: http://ci5.iarc. $\mathrm{fr} /$. Accessed 24.02.13.

4. Dikshit R, Gupta PC, Ramasundarahettige C, et al. Cancer mortality in India: a nationally representative survey. Lancet. 2012;379(9828):1807-1816.

5. El-Serag HB. Hepatocellular carcinoma. $N$ Engl J Med. 2011;365(12):1118-1127. http://dx.doi.org/10.1056/ NEJMra1001683.

6. El-Serag HB, Rudolph KL. Hepatocellular carcinoma: epidemiology and molecular carcinogenesis. Gastroenterology. 2007;132(7):2557-2576. http://dx.doi.org/10.1053/j.gastro. 2007.04 .061$.

7. Paul SB, Sreenivas V, Gulati MS, et al. Incidence of hepatocellular carcinoma among Indian patients with cirrhosis of liver: an experience from a tertiary care center in northern India. Indian J Gastroenterol. 2007;26(6):274-278.

8. Yeole BB. Trends in cancer incidence in esophagus, stomach, coIon, rectum and liver in males in India. Asian Pac J Cancer Prev. 2008:9(1):97-100.

9. Herbst DA, Reddy KR. Risk factors for hepatocellular carcinoma. Clin Liver Dis. 2012;1(6):180-182.

10. Nayak NC. Hepatocellular carcinoma-a model of human cancer: clinico-pathological features, etiology and pathogenesis. Indian J Pathol Microbiol. 2003;46(1):1-16.

11. Yang W-S, Va P, Bray F, et al. The role of pre-existing diabetes mellitus on hepatocellular carcinoma occurrence and prognosis: a meta-analysis of prospective cohort studies. PLOS ONE. 2011;6(12):e27326. http://dx.doi.org/10.1371/journal.pone. 0027326.

12. Wang $P$, Kang D, Cao W, Wang Y, Liu Z. Diabetes mellitus and risk of hepatocellular carcinoma: a systematic review and meta-analysis. Diabetes Metab Res Rev. 2012;28(2):109-122. http://dx. doi.org/10.1002/dmrr.1291.

13. Wang $C$, Wang $X$, Gong $G$, et al. Increased risk of hepatocellular carcinoma in patients with diabetes mellitus: a systematic review and meta-analysis of cohort studies. Int $J$ Cancer. 2012;130(7):1639-1648. http://dx.doi.org/10.1002/ijc. 26165. 
14. Sundaram C, Reddy CR, Ramana GV, et al. Hepatitis B surface antigen, hepatocellular carcinoma and cirrhosis in south India—an autopsy study. Indian J Pathol Microbiol. 1990;33(4):334-338.

15. Ramesh R, Munshi A, Panda SK. Prevalence of hepatitis $C$ virus antibodies in chronic liver disease and hepatocellular carcinoma patients in India. J Gastroenterol Hepatol. 1992;7(4):393-395.

16. Sarin SK, Thakur V, Guptan RC, et al. Profile of hepatocellular carcinoma in India: an insight into the possible etiologic associations. J Gastroenterol Hepatol. 2001;16(6):666-673.

17. Saini N, Bhagat A, Sharma S, Duseja A, Chawla Y. Evaluation of clinical and biochemical parameters in hepatocellular carcinoma: experience from an Indian center. Clin Chim Acta. 2006;371(12):183-186. http://dx.doi.org/10.1016/j.cca.2006.02.038.

18. Kumar M, Kumar R, Hissar SS, et al. Risk factors analysis for hepatocellular carcinoma in patients with and without cirrhosis: a case-control study of 213 hepatocellular carcinoma patients from India. J Gastroenterol Hepatol. 2007;22(7):1104-1111. http://dx.doi.org/10.1111/j.1440-1746.2007.04908.x.

19. Murugavel KG, Naranatt PP, Shankar EM, et al. Prevalence of aflatoxin B1 in liver biopsies of proven hepatocellular carcinoma in India determined by an in-house immunoperoxidase test. J Med Microbiol. 2007;56(Pt 11):1455-1459. http://dx.doi.org/10. 1099/jmm.0.47151-0.

20. Kumar R, Saraswat MK, Sharma BC, Sakhuja P, Sarin SK. Characteristics of hepatocellular carcinoma in India: a retrospective analysis of 191 cases. QJM. 2008;101(6):479-485. http://dx. doi.org/10.1093/qjmed/hcn033.

21. Paul SB, Chalamalasetty SB, Vishnubhatla S, et al. Clinical profile, etiology and therapeutic outcome in 324 hepatocellular carcinoma patients at a tertiary care center in India. Oncology. 2009;77(3-4):162-171. http://dx.doi.org/10.1159/ 000231886.

22. Asim M, Sarma MP, Thayumanavan L, Kar P. Role of aflatoxin B1 as a risk for primary liver cancer in north Indian population. Clin Biochem. 2011;44(14-15):1235-1240. http://dx.doi.org/10. 1016/j.clinbiochem.2011.07.017.

23. Sarma MP, Asim M, Medhi S, Bharathi T, Kar P. Hepatitis C virus related hepatocellular carcinoma: a case control study from India. J Med Virol. 2012;84(7):1009-1017. http://dx.doi.org/10. 1002/jmv.23290.

24. Jain D, Nayak NC, Saigal S. Hepatocellular carcinoma in nonalcoholic fatty liver cirrhosis and alcoholic cirrhosis: risk factor analysis in liver transplant recipients. Eur J Gastroenterol Hepatol. 2012;24(7):840-848. http://dx.doi.org/10.1097/MEG. Ob013e3283534b40.

25. Nayak NC, Jain D, Vasdev N, Gulwani H, Saigal S, Soin A. Etiologic types of end-stage chronic liver disease in adults: analysis of prevalence and their temporal changes from a study on native liver explants. Eur J Gastroenterol Hepatol. 2012;24(10):1199-1208. http://dx.doi.org/10.1097/MEG.0b013e32835643f1.

26. Asim M, Sarma MP, Kar P. Etiological and molecular profile of hepatocellular cancer from India. Int $J$ Cancer. 2013;133(2):437-445. http://dx.doi.org/10.1002/ijc.27993.

27. Duseja A, Sharma B, Kumar A, et al. Nonalcoholic fatty liver in a developing country is responsible for significant liver disease. Hepatology. 2010;52(6):2248-2249. http://dx.doi.org/10. 1002/hep.23838.

28. Amarapurkar DN, Patel ND, Kamani PM. Impact of diabetes mellitus on outcome of HCC. Ann Hepatol. 2008;7(2):148-151.

29. Amarapurkar D, Das HS. Chronic liver disease in diabetes mellitus. Trop Gastroenterol. 2002;23(1):3-5.

30. Asim M, Khan LA, Husain SA, et al. Genetic polymorphism of glutathione S transferases M1 and T1 in Indian patients with hepatocellular carcinoma. Dis Markers. 2010;28(6):369-376. http://dx.doi.org/10.3233/DMA-2010-0717.
31. Bharadwaj M, Roy G, Dutta K, Misbah M, Husain M, Hussain S. Tackling hepatitis B virus-associated hepatocellular carcinoma - the future is now. Cancer Metastasis Rev. 2013;32(1-2):229-268. http://dx.doi.org/10.1007/s10555-012-9412-6.

32. Jayshree RS, Sridhar H, Devi GM. Surface, core, and X genes of hepatitis $B$ virus in hepatocellular carcinoma: an in situ hybridization study. Cancer. 2003;99(1):63-67. http://dx.doi.org/10. 1002/cncr.10954.

33. Ramesh R, Panda SK, Jameel S, Rajasambandam P. Mapping of the hepatitis B virus genome in hepatocellular carcinoma using PCR and demonstration of a potential trans-activator encoded by the frequently detected fragment. J Gen Virol. 1994;75(Pt 2):327-334.

34. Asim M, Malik A, Sarma MP, et al. Hepatitis B virus BCP, precore/ core, $\mathrm{X}$ gene mutations/genotypes and the risk of hepatocellular carcinoma in India. J Med Virol. 2010;82(7):1115-1125. http:// dx.doi.org/10.1002/jmv.21774.

35. Kiran M, Chawla YK, Kaur J. Methylation profiling of tumor suppressor genes and oncogenes in hepatitis virus-related hepatocellular carcinoma in northern India. Cancer Genet Cytogenet. 2009;195(2):112-119. http://dx.doi.org/10.1016/j.cancergencyto.2009.06.021

36. Saini N, Srinivasan R, Chawla Y, Sharma S, Chakraborti A, Rajwanshi A. Telomerase activity, telomere length and human telomerase reverse transcriptase expression in hepatocellular carcinoma is independent of hepatitis virus status. Liver Int. 2009;29(8):1162-1170. http://dx.doi.org/10.1111/j.14783231.2009.02082.x.

37. Sarin SK, Kumar M. Predictive scores for hepatocellular carcinoma development in chronic hepatitis B virus infection: "does one size fit all?". Gastroenterology. 2012;142(4):1038-1040. http://dx.doi.org/10.1053/j.gastro.2012.02.024.

38. Poduri CD. Hepatitis C virus (HCV)—a review molecular biology of the virus, immunodiagnostics, genomic heterogeneity and the role of virus in hepatocellular carcinoma. Indian J Exp Biol. 2003;41(6):549-562.

39. Kiran M, Chawla YK, Kaur J. Glutathione-S-transferase and microsomal epoxide hydrolase polymorphism and viral-related hepatocellular carcinoma risk in India. DNA Cell Biol. 2008;27(12):687694. http://dx.doi.org/10.1089/dna.2008.0805.

40. Katiyar S, Dash BC, Thakur V, Guptan RC, Sarin SK, Das BC. P53 tumor suppressor gene mutations in hepatocellular carcinoma patients in India. Cancer. 2000;88(7):1565-1573.

41. Mohana Devi S, Balachandar V, Arun M, Suresh Kumar S, Balamurali Krishnan B, Sasikala K. Analysis of genetic damage and gene polymorphism in hepatocellular carcinoma (HCC) patients in a South Indian population. Dig Dis Sci. 2013;58(3):759-767. http://dx.doi.org/10.1007/s10620012-2409-8.

42. Kiran M, Saxena R, Chawla YK, Kaur J. Polymorphism of DNA repair gene XRCC1 and hepatitis-related hepatocellular carcinoma risk in Indian population. Mol Cell Biochem. 2009;327(12):7-13. http://dx.doi.org/10.1007/s11010-009-0035-3.

43. Kiran M, Chawla YK, Jain M, Kaur J. Haplotypes of microsomal epoxide hydrolase and X-ray cross-complementing group 1 genes in Indian hepatocellular carcinoma patients. DNA Cell Biol. 2009;28(11):573-577. http://dx.doi.org/10.1089/dna.2009. 0921.

44. Paul SB, Sreenivas V, Gulati MS, et al. Economic evaluation of a surveillance program of hepatocellular carcinoma (HCC) in India. Hepatol Int. 2008;2(2):231-236. http://dx.doi.org/10.1007/ s12072-008-9054-5.

45. Chang MH, Chen CJ, Lai MS, et al. Universal hepatitis B vaccination in Taiwan and the incidence of hepatocellular carcinoma in children. Taiwan Childhood Hepatoma Study Group. N Engl $J$ 
Med. 1997;336(26):1855-1859. http://dx.doi.org/10.1056/ NEJM199706263362602.

46. Liaw Y-F, Sung JJY, Chow WC, et al. Lamivudine for patients with chronic hepatitis B and advanced liver disease. $N$ Engl $J$ Med. 2004;351(15):1521-1531. http://dx.doi.org/10.1056/NEJMoa033364.

47. Lai C-L, Yuen M-F. Prevention of hepatitis B virus-related hepatocellular carcinoma with antiviral therapy. Hepatology. 2013;57(1):399-408. http://dx.doi.org/10.1002/hep.25937.

48. Chakrabarty SP, Murray JM. Modelling hepatitis $\mathrm{C}$ virus infection and the development of hepatocellular carcinoma. J Theor Biol. 2012;305:24-29. http://dx.doi.org/10.1016/j.jtbi.2012.03.030.

49. Singal AG, Volk ML, Jensen D, Di Bisceglie AM, Schoenfeld PS. A sustained viral response is associated with reduced liverrelated morbidity and mortality in patients with hepatitis $\mathrm{C}$ virus. Clin Gastroenterol Hepatol. 2010;8(3):280-288. http://dx.doi. org/10.1016/j.cgh.2009.11.018, 288.e1.

50. Singal AK, Singh A, Jaganmohan S, et al. Antiviral therapy reduces risk of hepatocellular carcinoma in patients with hepatitis $C$ virusrelated cirrhosis. Clin Gastroenterol Hepatol. 2010;8(2):192199. http://dx.doi.org/10.1016/j.cgh.2009.10.026.

51. Di Bisceglie AM, Shiffman ML, Everson GT, et al. Prolonged therapy of advanced chronic hepatitis $C$ with low-dose peginterferon. N Engl J Med. 2008;359(23):2429-2441. http://dx.doi.org/10. 1056/NEJMoa0707615.

52. Morgan RL, Baack B, Smith BD, Yartel A, Pitasi M, Falck-Ytter Y. Eradication of hepatitis $C$ virus infection and the development of hepatocellular carcinoma: a meta-analysis of observational studies. Ann Intern Med. 2013;158(5 Pt 1):329-337. http:// dx.doi.org/10.7326/0003-4819-158-5-201303050-00005.

53. De Lope CR, Tremosini S, Forner A, Reig M, Bruix J. Management of HCC. J Hepatol. 2012;56(suppl 1):S75-S87. http://dx.doi. org/10.1016/S0168-8278(12)60009-9.

54. Llovet JM, Burroughs A, Bruix J. Hepatocellular carcinoma. Lancet. 2003;362(9399):1907-1917. http://dx.doi.org/10.1016/ S0140-6736(03)14964-1.

55. Forner A, Llovet JM, Bruix J. Hepatocellular carcinoma. Lancet. 2012;379(9822):1245-1255. http://dx.doi.org/10.1016/ S0140-6736(11)61347-0.

56. El-Serag HB. Surveillance for hepatocellular carcinoma: Iong way to achieve effectiveness. Dig Dis Sci. 2012;57(12):3050-3051. http://dx.doi.org/10.1007/s10620-012-2413-z.

57. Croswell JM, Ransohoff DF, Kramer BS. Principles of cancer screening: lessons from history and study design issues. Semin Oncol. 2010;37(3):202-215. http://dx.doi.org/10.1053/j. seminoncol.2010.05.006.

58. Zhang B-H, Yang B-H, Tang Z-Y. Randomized controlled trial of screening for hepatocellular carcinoma. J Cancer Res Clin Oncol. 2004;130(7):417-422. http://dx.doi.org/10.1007/s00432004-0552-0.

59. Aghoram R, Cai P, Dickinson JA. Alpha-foetoprotein and/or liver ultrasonography for screening of hepatocellular carcinoma in patients with chronic hepatitis B. Cochrane Database Syst Rev. 2012;9:CD002799. http://dx.doi.org/10.1002/14651858. CD002799.pub2.

60. Trevisani F, Cantarini MC, Labate AMM, et al. Surveillance for hepatocellular carcinoma in elderly Italian patients with cirrhosis: effects on cancer staging and patient survival. Am J Gastroenterol. 2004;99(8):1470-1476. http://dx.doi.org/10.1111/j.15720241.2004.30137.x.

61. Yuen MF, Cheng CC, Lauder IJ, Lam SK, Ooi CG, Lai CL. Early detection of hepatocellular carcinoma increases the chance of treatment: Hong Kong experience. Hepatology. 2000;31(2):330-335. http://dx.doi.org/10.1002/hep.510310211.
62. Wong LL, Limm WM, Severino R, Wong LM. Improved survival with screening for hepatocellular carcinoma. Liver Transpl. 2000;6(3):320-325. http://dx.doi.org/10.1053/lv.2000.4875.

63. Sangiovanni A, Del Ninno E, Fasani P, et al. Increased survival of cirrhotic patients with a hepatocellular carcinoma detected during surveillance. Gastroenterology. 2004;126(4):1005-1014.

64. Trevisani F, Santi V, Gramenzi A, et al. Surveillance for early diagnosis of hepatocellular carcinoma: is it effective in intermediate/ advanced cirrhosis? Am J Gastroenterol. 2007;102(11):24482457. http://dx.doi.org/10.1111/j.1572-0241.2007.01395.x. quiz 2458.

65. Trevisani F, De NS, Rapaccini G, et al. Semiannual and annual surveillance of cirrhotic patients for hepatocellular carcinoma: effects on cancer stage and patient survival (Italian experience). Am J Gastroenterol. 2002;97(3):734-744. http://dx.doi.org/10. 1111/j.1572-0241.2002.05557.x.

66. Sarasin FP, Giostra E, Hadengue A. Cost-effectiveness of screening for detection of small hepatocellular carcinoma in western patients with Child-Pugh class A cirrhosis. Am J Med. 1996;101(4):422-434. http://dx.doi.org/10.1016/S00029343(96)00197-0.

67. Arguedas MR, Chen VK, Eloubeidi MA, Fallon MB. Screening for hepatocellular carcinoma in patients with hepatitis C cirrhosis: a cost-utility analysis. Am J Gastroenterol. 2003;98(3):679-690.

68. Lin OS, Keeffe EB, Sanders GD, Owens DK. Cost-effectiveness of screening for hepatocellular carcinoma in patients with cirrhosis due to chronic hepatitis C. Aliment Pharmacol Ther. 2004;19(11):1159-1172. http://dx.doi.org/10.1111/j.13652036.2004.01963.x.

69. Ruggeri M. Hepatocellular carcinoma: cost-effectiveness of screening. A systematic review. Risk Manag Healthc Policy. 2012;5:49-54. http://dx.doi.org/10.2147/RMHP.S18677.

70. Amarapurkar D, Han K-H, Chan HL-Y, Ueno Y. Application of surveillance programs for hepatocellular carcinoma in the Asia-Pacific Region. J Gastroenterol Hepatol. 2009;24(6):955-961. http://dx.doi.org/10.1111/j.1440-1746.2009.05805.x.

71. White DL, Kanwal F, El-Serag HB. Association between nonalcoholic fatty liver disease and risk for hepatocellular cancer, based on systematic review. Clin Gastroenterol Hepatol. 2012;10(12):1342-1359. http://dx.doi.org/10.1016/j.cgh. 2012.10.001. e2.

72. Singal A, Volk ML, Waljee A, et al. Meta-analysis: surveillance with ultrasound for early-stage hepatocellular carcinoma in patients with cirrhosis. Aliment Pharmacol Ther. 2009;30(1):37-47. http://dx.doi.org/10.1111/j.1365-2036.2009.04014.x.

73. Sheu JC, Sung JL, Chen DS, et al. Growth rate of asymptomatic hepatocellular carcinoma and its clinical implications. Gastroenterology. 1985;89(2):259-266.

74. Trinchet J-C, Chaffaut C, Bourcier V, et al. Ultrasonographic surveillance of hepatocellular carcinoma in cirrhosis: a randomized trial comparing 3- and 6-month periodicities. Hepatology. 2011;54(6):1987-1997. http://dx.doi.org/10.1002/hep.24545.

75. Han KH, Kim do Y, Park JY, Ahn SH, Kim J, Kim SU, et al. Survival of hepatocellular carcinoma patients may be improved in surveillance interval not more than 6 months compared with more than 6 months: a 15-year prospective study. J Clin Gastroenterol. 2013;47(6):538-544. Ob013e3182755c13.

76. Trevisani F, D'Intino PE, Morselli-Labate AM, et al. Serum alphafetoprotein for diagnosis of hepatocellular carcinoma in patients with chronic liver disease: influence of HBsAg and anti-HCV status. J Hepatol. 2001;34(4):570-575.

77. Marrero JA, Feng Z, Wang Y, et al. Alpha-fetoprotein, des-gamma carboxyprothrombin, and lectin-bound alpha-fetoprotein in early 
hepatocellular carcinoma. Gastroenterology. 2009;137(1):110118. http://dx.doi.org/10.1053/j.gastro.2009.04.005.

78. Lok AS, Sterling RK, Everhart JE, et al. Des-gamma-carboxy prothrombin and alpha-fetoprotein as biomarkers for the early detection of hepatocellular carcinoma. Gastroenterology. 2010;138(2):493502. http://dx.doi.org/10.1053/j.gastro.2009.10.031.

79. Di Bisceglie AM, Sterling RK, Chung RT, et al. Serum alphafetoprotein levels in patients with advanced hepatitis C: results from the HALT-C Trial. J Hepatol. 2005;43(3):434-441.

80. Tsukuma H, Hiyama T, Tanaka S, et al. Risk factors for hepatocellular carcinoma among patients with chronic liver disease. $N$ Engl J Med. 1993;328(25):1797-1801. http://dx.doi.org/10.1056/ NEJM199306243282501.

81. Zhou X-D, Tang Z-Y, Fan J, et al. Intrahepatic cholangiocarcinoma: report of 272 patients compared with 5,829 patients with hepatocellular carcinoma. J Cancer Res Clin Oncol. 2009;135(8):10731080. http://dx.doi.org/10.1007/s00432-009-0547-y.

82. Paul SB, Gulati MS, Sreenivas V, et al. Evaluating patients with cirrhosis for hepatocellular carcinoma: value of clinical symptomatology, imaging and alpha-fetoprotein. Oncology. 2007;72(suppl 1):117-123. http://dx.doi.org/10.1159/000111717.

83. Kudo M, Izumi N, Kokudo N, et al. Management of hepatocellular carcinoma in Japan: Consensus-Based Clinical Practice Guidelines proposed by the Japan Society of Hepatology (JSH) 2010 updated version. Dig Dis. 2011;29(3):339-364. http://dx.doi.org/ 10.1159/000327577.

84. Paul SB, Jaganathan S, Hasan A, et al. Evaluation of hepatocellular carcinoma by contrast enhanced ultrasound: a novel technique. Trop Gastroenterol. 2010;31(3):213-216.

85. Hatanaka K, Kudo M, Minami Y, et al. Differential diagnosis of hepatic tumors: value of contrast-enhanced harmonic sonography using the newly developed contrast agent, Sonazoid. Intervirology. 2008;51(suppl 1):61-69. http://dx.doi.org/10.1159/ 000122600.

86. Colli A, Fraquelli M, Casazza G, et al. Accuracy of ultrasonography, spiral CT, magnetic resonance, and alpha-fetoprotein in diagnosing hepatocellular carcinoma: a systematic review. Am J Gastroenterol. 2006;101(3):513-523. http://dx.doi.org/10.1111/ j.1572-0241.2006.00467.x.

87. Forner A, Vilana R, Ayuso C, et al. Diagnosis of hepatic nodules $20 \mathrm{~mm}$ or smaller in cirrhosis: prospective validation of the noninvasive diagnostic criteria for hepatocellular carcinoma. Hepatology. 2008;47(1):97-104. http://dx.doi.org/10.1002/hep.21966.

88. Sangiovanni A, Manini MA, lavarone M, et al. The diagnostic and economic impact of contrast imaging techniques in the diagnosis of small hepatocellular carcinoma in cirrhosis. Gut. 2010;59(5):638644. http://dx.doi.org/10.1136/gut.2009.187286.

89. Khalili K, Kim TK, Jang H-J, et al. Optimization of imaging diagnosis of 1-2 cm hepatocellular carcinoma: an analysis of diagnostic performance and resource utilization. J Hepatol. 2011;54(4):723-728. http://dx.doi.org/10.1016/j.jhep.2010. 07.025 .

90. Paul SB, Gulati MS. Spectrum of hepatocellular carcinoma on triple phase helical CT: a pictorial essay. Clin Imaging. 2002;26(4):270-279.

91. Karak PK, Mukhopadhyay S, Berry M. Hepatocellular carcinomaimage morphology in 40 patients. Trop Gastroenterol. 1992;13(1):21-26.

92. Bhargava DK, Verma K, Dasarathy S. Laparoscopic \& histological features of hepatocellular carcinoma. Indian J Med Res. 1991;94:424-425.

93. Lagana SM, Salomao M, Bao F, Moreira RK, Lefkowitch JH, Remotti HE. Utility of an immunohistochemical panel consisting of Glypican-3, heat-shock protein-70, and glutamine synthetase in the distinction of low-grade hepatocellular carcinoma from he- patocellular adenoma. Appl Immunohistochem Mol Morphol. 2013;21(2):173-179. $\quad$ http://dx.doi.org/10.1097/PAl. Ob013e31825d527f.

94. Ahuja A, Gupta N, Kalra N, Srinivasan R, Chawla Y, Rajwanshi A. Role of CD10 immunochemistry in differentiating hepatocellular carcinoma from metastatic carcinoma of the liver. Cytopathology. 2008;19(4):229-235. http://dx.doi.org/10.1111/j.13652303.2007.00520.x.

95. Swamy MC, Arathi C, Kodandaswamy C. Value of ultrasonographyguided fine needle aspiration cytology in the investigative sequence of hepatic lesions with an emphasis on hepatocellular carcinoma. J Cytol. 2011;28(4):178-184. http://dx.doi.org/10. 4103/0970-9371.86344.

96. Saraswathi A, Malati T. Clinical relevance of alphafetoprotein microheterogeneity in alphafetoprotein-secreting tumors. Cancer Detect Prev. 1994;18(6):447-454.

97. Nayak SS, Kamath SS, Kundaje GN, Aroor AR. Diagnostic significance of estimation of serum apolipoprotein A along with alphafetoprotein in alcoholic cirrhosis and hepatocellular carcinoma patients. Clin Chim Acta. 1988;173(2):157-164.

98. Murugavel KG, Mathews S, Jayanthi V, et al. Alpha-fetoprotein as a tumor marker in hepatocellular carcinoma: investigations in south Indian subjects with hepatotropic virus and aflatoxin etiologies. Int J Infect Dis. 2008;12(6):e71-76. http://dx.doi.org/ 10.1016/j.ijid.2008.04.010.

99. Jiang T, Zhu AX, Sahani DV. Established and novel imaging biomarkers for assessing response to therapy in hepatocellular carcinoma. J Hepatol. 2013;58(1):169-177. http://dx.doi.org/10. 1016/j.jhep.2012.08.022.

100. Talbot J-N, Fartoux L, Balogova S, et al. Detection of hepatocellular carcinoma with PET/CT: a prospective comparison of 18F-fluorocholine and 18F-FDG in patients with cirrhosis or chronic liver disease. J Nucl Med. 2010;51(11):1699-1706. http://dx.doi. org/10.2967/jnumed.110.075507.

101. Olthoff KM, Forner A, Hübscher S, Fung J. What is the best staging system for hepatocellular carcinoma in the setting of liver transplantation? Liver Transpl. 2011;17(suppl 2):S26-S33. http:// dx.doi.org/10.1002/It.22352.

102. Llovet JM, Brú C, Bruix J. Prognosis of hepatocellular carcinoma: the BCLC staging classification. Semin Liver Dis. 1999;19(3):329-338. http://dx.doi.org/10.1055/s-20071007122.

103. Forner A, Rodríguez-Lopez C, Reig M. Natural history and staging for hepatocellular carcinoma. Clin Liver Dis. 2012;1:183-185.

104. Sarma S, Sharma B, Chawla YK, et al. Comparison of 7 staging systems in north Indian cohort of hepatocellular carcinoma. Trop Gastroenterol. 2010;31(4):271-278.

105. Ho C, Chen S, Yeung DWC, Cheng TKC. Dual-tracer PET/CT imaging in evaluation of metastatic hepatocellular carcinoma. J Nucl Med. 2007;48(6):902-909. http://dx.doi.org/10.2967/ jnumed.106.036673.

106. Pal S, Pande GK. Current status of surgery and transplantation in the management of hepatocellular carcinoma: an overview. J Hepatobiliary Pancreat Surg. 2001;8(4):323-336. http://dx. doi.org/10.1007/s0053410080323.

107. Parikh P, Malhotra H, Jelic S. Hepatocellular carcinoma: ESMO clinical recommendations for diagnosis, treatment and followup. Ann Oncol. 2008;19(suppl 2):ii27-28. http://dx.doi.org/ 10.1093/annonc/mdn114.

108. Llovet JM, Fuster J, Bruix J. Intention-to-treat analysis of surgical treatment for early hepatocellular carcinoma: resection versus transplantation. Hepatology. 1999;30(6):1434-1440. http:// dx.doi.org/10.1002/hep.510300629.

109. Llovet JM, Schwartz M, Mazzaferro V. Resection and liver transplantation for hepatocellular carcinoma. Semin Liver Dis. 
2005;25(2):181-200. http://dx.doi.org/10.1055/s-2005871198.

110. Shukla PJ, Barreto SG. Surgery for malignant liver tumors. J Cancer Res Ther. 2009;5(3):154-160. http://dx.doi.org/10. 4103/0973-1482.57119.

111. Marwah S, Khan MMR, Chaudhary A, et al. Two hundred and fortyone consecutive liver resections: an experience from India. HPB (Oxford). 2007;9(1):29-36. http://dx.doi.org/10.1080/ 13651820600985259.

112. Yao FY, Ferrell L, Bass NM, et al. Liver transplantation for hepatocellular carcinoma: expansion of the tumor size limits does not adversely impact survival. Hepatology. 2001;33(6):1394-1403. http://dx.doi.org/10.1053/jhep.2001.24563.

113. Liu F, Wei Y, Wang W, et al. Salvage liver transplantation for recurrent hepatocellular carcinoma within UCSF criteria after liver resection. PLOS ONE. 2012;7(11):e48932. http://dx.doi.org/ 10.1371/journal.pone.0048932.

114. Abdo AA, Hassanain M, AlJumah A, et al. Saudi guidelines for the diagnosis and management of hepatocellular carcinoma: technical review and practice guidelines. Ann Saudi Med. 2012;32(2):174-199.

115. EASL-EORTC clinical practice guidelines: management of hepatocellular carcinoma. J Hepatol. 2012;56(4):908-943. http://dx. doi.org/10.1016/j.jhep.2011.12.001.

116. Mazzaferro V, Regalia E, Doci R, et al. Liver transplantation for the treatment of small hepatocellular carcinomas in patients with cirrhosis. N Engl J Med. 1996;334(11):693-699. http://dx.doi. org/10.1056/NEJM199603143341104.

117. Jonas S, Bechstein WO, Steinmüller T, et al. Vascular invasion and histopathologic grading determine outcome after liver transplantation for hepatocellular carcinoma in cirrhosis. Hepatology. 2001;33(5):1080-1086. http://dx.doi.org/10.1053/jhep. 2001.23561.

118. Befeler AS, Hayashi PH, Di Bisceglie AM. Liver transplantation for hepatocellular carcinoma. Gastroenterology. 2005;128(6):17521764.

119. Mazzaferro V, Bhoori S, Sposito C, et al. Milan criteria in liver transplantation for hepatocellular carcinoma: an evidence-based analysis of 15 years of experience. Liver Transpl. 2011;17(suppl 2):S44-S57. http://dx.doi.org/10.1002/It.22365.

120. Chan SC, Fan ST, Chok KS, Cheung TT, Chan AC, Fung JY, et al. Survival advantage of primary liver transplantation for hepatocellular carcinoma within the up-to-7 criteria with microvascular invasion. Hepatol Int. 2012;6(3):646-656.

121. Landman MP, Feurer ID, Pinson CW, Moore DE. Which is more cost-effective under the MELD system: primary liver transplantation, or salvage transplantation after hepatic resection or after loco-regional therapy for hepatocellular carcinoma within Milan criteria? HPB (Oxford). 2011;13(11):783-791. http://dx.doi. org/10.1111/j.1477-2574.2011.00355.x.

122. Clavien P-A, Lesurtel M, Bossuyt PMM, Gores GJ, Langer B, Perrier A. Recommendations for liver transplantation for hepatocellular carcinoma: an international consensus conference report. Lancet Oncol. 2012;13(1):e11-22. http://dx.doi.org/ 10.1016/S1470-2045(11)70175-9.

123. Yao FY, Xiao L, Bass NM, Kerlan R, Ascher NL, Roberts JP. Liver transplantation for hepatocellular carcinoma: validation of the UCSF-expanded criteria based on preoperative imaging. Am J Transplant. 2007;7(11):2587-2596. http://dx.doi.org/10. 1111/j.1600-6143.2007.01965.x.

124. Volk ML, Vijan S, Marrero JA. A novel model measuring the harm of transplanting hepatocellular carcinoma exceeding Milan criteria. Am J Transplant. 2008;8(4):839-846. http://dx.doi.org/10. 1111/j.1600-6143.2007.02138.x.
125. Llovet JM, Mas X, Aponte JJ, et al. Cost effectiveness of adjuvant therapy for hepatocellular carcinoma during the waiting list for liver transplantation. Gut. 2002;50(1):123-128.

126. Majno P, Giostra E, Mentha G. Management of hepatocellular carcinoma on the waiting list before liver transplantation: time for controlled trials? Liver Transpl. 2007;13(11 suppl 2):S27-S35. http://dx.doi.org/10.1002/lt.21328.

127. Kaihara S, Kiuchi T, Ueda M, et al. Living-donor liver transplantation for hepatocellular carcinoma. Transplantation. 2003;75(3 suppl I):S37-S40. http://dx.doi.org/10.1097/01.TP. 0000047029.02806 .16 .

128. Todo S, Furukawa H. Living donor liver transplantation for adult patients with hepatocellular carcinoma: experience in Japan. Ann Surg. 2004;240(3):451-459. discussion 459-461.

129. Wakade VA, Mathur SK. Donor safety in live-related liver transplantation. Indian J Surg. 2012;74(1):118-126. http://dx.doi. org/10.1007/s12262-011-0385-4.

130. Kakodkar R, Soin AS. Liver transplantation for HCC: a review. Indian J Surg. 2012;74(1):100-117. http://dx.doi.org/10.1007/ s12262-011-0387-2.

131. Yu C-Y, Ou H-Y, Huang T-L, et al. Hepatocellular carcinoma downstaging in liver transplantation. Transplant Proc. 2012;44(2):412414. http://dx.doi.org/10.1016/j.transproceed.2012.01.043.

132. Lai Q, Avolio AW, Manzia TM, et al. Combination of biological and morphological parameters for the selection of patients with hepatocellular carcinoma waiting for liver transplantation. Clin Transplant. 2012;26(2):E125-E131. http://dx.doi.org/10.1111/j. 1399-0012.2011.01572.x.

133. Toso C, Asthana S, Bigam DL, Shapiro AMJ, Kneteman NM. Reassessing selection criteria prior to liver transplantation for hepatocellular carcinoma utilizing the Scientific Registry of Transplant Recipients Database. Hepatology. 2009;49(3):832-838. http://dx.doi.org/10.1002/hep.22693.

134. Hakeem AR, Young RS, Marangoni G, Lodge JP, Prasad KR. Systematic review: the prognostic role of alpha-fetoprotein following liver transplant for hepatocellular carcinoma. Aliment Pharmacol Ther. 2012 Mar $20 \mathrm{http}: / / d x . d o i . o r g / 10.1111 / \mathrm{j} .1365-2036$. 2012.05060.x.

135. Shrimal A, Prasanth M, Kulkarni AV. Interventional radiological treatment of hepatocellular carcinoma: an update. Indian J Surg. 2012;74(1):91-99. http://dx.doi.org/10.1007/s12262011-0377-4.

136. Paul SB, Gamanagatti SR, Aneesh MK, Acharya SK. Percutaneous ablative therapy for hepatocellular carcinoma. Natl Med J India. 2011;24(6):347-355.

137. Sala M, Llovet JM, Vilana R, et al. Initial response to percutaneous ablation predicts survival in patients with hepatocellular carcinoma. Hepatology. 2004;40(6):1352-1360. http://dx.doi. org/10.1002/hep.20465.

138. Lencioni R. Loco-regional treatment of hepatocellular carcinoma. Hepatology. 2010;52(2):762-773. http://dx.doi.org/10.1002/ hep. 23725.

139. Livraghi T, Bolondi L, Lazzaroni S, et al. Percutaneous ethanol injection in the treatment of hepatocellular carcinoma in cirrhosis. A study on 207 patients. Cancer. 1992;69(4):925-929.

140. Lencioni R, Bartolozzi C, Caramella D, et al. Treatment of small hepatocellular carcinoma with percutaneous ethanol injection. Analysis of prognostic factors in 105 western patients. Cancer. 1995;76(10):1737-1746.

141. Livraghi T, Giorgio A, Marin G, et al. Hepatocellular carcinoma and cirrhosis in 746 patients: long-term results of percutaneous ethanol injection. Radiology. 1995;197(1):101-108.

142. Khan KN, Yatsuhashi H, Yamasaki K, et al. Prospective analysis of risk factors for early intrahepatic recurrence of hepatocellular 
carcinoma following ethanol injection. J Hepatol. 2000;32(2):269-278.

143. Huo TI, Huang YH, Wu JC, Lee PC, Chang FY, Lee SD. Comparison of percutaneous acetic acid injection and percutaneous ethanol injection for hepatocellular carcinoma in cirrhotic patients: a prospective study. Scand J Gastroenterol. 2003;38(7):770-778.

144. Lencioni R, Cioni D, Crocetti L, et al. Early-stage hepatocellular carcinoma in patients with cirrhosis: long-term results of percutaneous image-guided radiofrequency ablation. Radiology. 2005;234(3):961-967. http://dx.doi.org/10.1148/radiol. 2343040350 .

145. Omata M, Tateishi R, Yoshida H, Shiina S. Treatment of hepatocellular carcinoma by percutaneous tumor ablation methods: ethanol injection therapy and radiofrequency ablation. Gastroenterology. 2004;127(5 suppl 1):S159-S166.

146. N'Kontchou G, Mahamoudi A, Aout M, et al. Radiofrequency ablation of hepatocellular carcinoma: long-term results and prognostic factors in 235 western patients with cirrhosis. Hepatology. 2009;50(5):1475-1483. http://dx.doi.org/10.1002/hep.23181.

147. Cho YK, Kim JK, Kim MY, Rhim H, Han JK. Systematic review of randomized trials for hepatocellular carcinoma treated with percutaneous ablation therapies. Hepatology. 2009;49(2):453-459. http://dx.doi.org/10.1002/hep.22648.

148. Germani G, Pleguezuelo M, Gurusamy K, Meyer T, Isgrò G, Burroughs AK. Clinical outcomes of radiofrequency ablation, percutaneous alcohol and acetic acid injection for hepatocellular carcinoma: a meta-analysis. J Hepatol. 2010;52(3):380-388. http://dx.doi.org/10.1016/j.jhep.2009.12.004.

149. Bouza C, López-Cuadrado T, Alcázar R, Saz-Parkinson Z, Amate JM. Meta-analysis of percutaneous radiofrequency ablation versus ethanol injection in hepatocellular carcinoma. BMC Gastroenterol. 2009;9:31. http://dx.doi.org/10.1186/1471230X-9-31.

150. Orlando A, Leandro G, Olivo M, Andriulli A, Cottone M. Radiofrequency thermal ablation vs. percutaneous ethanol injection for small hepatocellular carcinoma in cirrhosis: meta-analysis of randomized controlled trials. $\mathrm{Am} J$ Gastroenterol. 2009;104(2):514-524. http://dx.doi.org/10.1038/ajg. 2008.80.

151. Chhabra DG, Shah RC, Parikh V, Jagannath P. Radiofrequency ablation of liver tumors: experience with open and percutaneous approach. Indian J Gastroenterol. 2006;25(2):66-70.

152. Gulati MS, Batra Y, Paul SB, Madan K, Ahuja V, Kaul HK. Radiofrequency ablation: a new therapeutic modality for the management of hepatocellular cancer. Trop Gastroenterol. 2002;23(4):183185.

153. Tateishi R, Shiina S, Teratani T, et al. Percutaneous radiofrequency ablation for hepatocellular carcinoma. An analysis of 1000 cases. Cancer. 2005;103(6):1201-1209. http://dx. doi. org/10.1002/cncr.20892.

154. Kapoor A, Kapoor A, Mahajan G. Technical note: radiofrequency ablation of hepatocellular carcinoma with contrast-enhanced ultrasound guidance: first Indian experience. Indian J Radiol Imaging. 2011;21(2):121-123. http://dx.doi.org/10.4103/09713026.82296 .

155. EASL-EORTC clinical practice guidelines: management of hepatocellular carcinoma. Eur J Cancer. 2012;48(5):599-641. http:// dx.doi.org/10.1016/j.ejca.2011.12.021.

156. Chen M-S, Li J-Q, Zheng Y, et al. A prospective randomized trial comparing percutaneous local ablative therapy and partial hepatectomy for small hepatocellular carcinoma. Ann Surg. 2006;243(3):321-328. http://dx.doi.org/10.1097/01.sla. 0000201480.65519.b8.

157. Huang J, Yan L, Cheng Z, et al. A randomized trial comparing radiofrequency ablation and surgical resection for HCC conforming to the Milan criteria. Ann Surg. 2010;252(6):903-912. http://dx. doi.org/10.1097/SLA.0b013e3181efc656.

158. Maini S, Marwaha A. Modeling and simulation of novel antenna for the treatment of hepatocellular carcinoma using finite element method. Electromagn Biol Med. 2013 Sep;32(3):373-381. http://dx.doi.org/10.3109/15368378.2012.721849.

159. Paul SB, Manjunatha YC, Acharya SK. Palliative treatment in advanced hepatocellular carcinoma: has it made any difference? Trop Gastroenterol. 2009;30(3):125-134.

160. Srivastava DN, Thulkar S, Sharma S, et al. Therapeutic radiological interventional procedures in hepatocellular carcinoma. Indian J Gastroenterol. 2002;21(3):96-98.

161. Llovet JM, Real MI, Montaña X, et al. Arterial embolisation or chemoembolisation versus symptomatic treatment in patients with unresectable hepatocellular carcinoma: a randomised controlled trial. Lancet. 2002;359(9319):1734-1739. http://dx.doi.org/ 10.1016/S0140-6736(02)08649-X.

162. Lo C-M, Ngan H, Tso W-K, et al. Randomized controlled trial of transarterial lipiodol chemoembolization for unresectable hepatocellular carcinoma. Hepatology. 2002;35(5):1164-1171. http:// dx.doi.org/10.1053/jhep.2002.33156.

163. Takayasu K, Arii S, Ikai I, et al. Prospective cohort study of transarterial chemoembolization for unresectable hepatocellular carcinoma in 8510 patients. Gastroenterology. 2006;131(2):461469. http://dx.doi.org/10.1053/j.gastro.2006.05.021.

164. Paul SB, Guglani B, Gulati MS, Batra Y, Mukhopadhyay S. Transcatheter arterial chemoembolization in hepatocellular carcinoma: technique, effects and present status. Trop Gastroenterol. 2003;24(4):176-184.

165. Rammohan A, Sathyanesan J, Ramaswami S, et al. Embolization of liver tumors: past, present and future. World I Radiol. 2012;4(9):405-412. http://dx.doi.org/10.4329/wjr.v4.i9.405.

166. Lewandowski RJ, Geschwind J-F, Liapi E, Salem R. Transcatheter intraarterial therapies: rationale and overview. Radiology. 2011;259(3):641-657. http://dx.doi.org/10.1148/radiol. 11081489

167. Chung JW, Park JH, Han JK, et al. Hepatic tumors: predisposing factors for complications of transcatheter oily chemoembolization. Radiology. 1996;198(1):33-40.

168. Chan AO, Yuen M-F, Hui C-K, Tso W-K, Lai C-L. A prospective study regarding the complications of transcatheter intraarterial lipiodol chemoembolization in patients with hepatocellular carcinoma. Cancer. 2002;94(6):1747-1752.

169. Paul SB, Gamanagatti SR, Mukund A, Abbas SZ, Acharya SK Transarterial chemoembolization for hepatocellular carcinoma: significance of extrahepatic collateral supply. Indian J Cancer. 2011;48(3):339-344. http://dx.doi.org/10.4103/0019-509X. 84941.

170. A comparison of lipiodol chemoembolization and conservative treatment for unresectable hepatocellular carcinoma. Groupe d'Etude et de Traitement du Carcinome Hépatocellulaire. N Engl J Med. 1995;332(19):1256-1261. http://dx.doi.org/10.1056/ NEJM199505113321903.

171. Llovet JM, Bruix J. Systematic review of randomized trials for unresectable hepatocellular carcinoma: chemoembolization improves survival. Hepatology. 2003;37(2):429-442. http://dx. doi.org/10.1053/jhep.2003.50047.

172. Cammà $\mathrm{C}$, Schepis $\mathrm{F}$, Orlando $\mathrm{A}$, et al. Transarterial chemoembolization for unresectable hepatocellular carcinoma: meta-analysis of randomized controlled trials. Radiology. 2002;224(1):47-54.

173. Paul SB, Gamanagatti S, Sreenivas V, et al. Trans-arterial chemoembolization (TACE) in patients with unresectable hepatocellular carcinoma: experience from a tertiary care centre in India. Indian J Radiol Imaging. 2011;21(2):113-120. http://dx.doi.org/10. 4103/0971-3026.82294. 
174. Oliveri RS, Wetterslev J, Gluud C. Transarterial (chemo)embolisation for unresectable hepatocellular carcinoma. Cochrane Database Syst Rev. 2011;3:CD004787. http://dx.doi.org/10.1002/ 14651858.CD004787.pub2.

175. Varela M, Real MI, Burrel M, et al. Chemoembolization of hepatocellular carcinoma with drug eluting beads: efficacy and doxorubicin pharmacokinetics. J Hepatol. 2007;46(3):474-481. http://dx.doi.org/10.1016/j.jhep.2006.10.020.

176. Lammer J, Malagari K, VogI T, et al. Prospective randomized study of doxorubicin-eluting-bead embolization in the treatment of hepatocellular carcinoma: results of the PRECISION V study. Cardiovasc Intervent Radiol. 2010;33(1):41-52. http://dx.doi.org/10. 1007/s00270-009-9711-7.

177. Petruzzi NJ, Frangos AJ, Fenkel JM, et al. Single-center comparison of three chemoembolization regimens for hepatocellular carcinoma. J Vasc Interv Radiol. 2013;24(2):266-273. http://dx. doi.org/10.1016/j.jvir.2012.10.025.

178. Padia SA, Shivaram G, Bastawrous S, et al. Safety and efficacy of drug-eluting bead chemoembolization for hepatocellular carcinoma: comparison of small-versus medium-size particles. J Vasc Interv Radiol. 2013;24(3):301-306. http://dx.doi.org/ 10.1016/j.jvir.2012.11.023.

179. Prajapati HJ, Dhanasekaran R, El-Rayes BF, et al. Safety and efficacy of doxorubicin drug-eluting bead transarterial chemoembolization in patients with advanced hepatocellular carcinoma. J Vasc Interv Radiol. 2013;24(3):307-315. http://dx.doi.org/10. 1016/j.jvir.2012.11.026.

180. Vadot L, Boulin M, Malbranche C, et al. Result and cost of hepatic chemoembolisation with drug eluting beads in 21 patients. Diagn Interv Imaging. 2013;94(1):53-59. http://dx.doi.org/10.1016/ j.diii.2012.05.001.

181. Marelli L, Stigliano R, Triantos C, et al. Transarterial therapy for hepatocellular carcinoma: which technique is more effective? A systematic review of cohort and randomized studies. Cardiovasc Intervent Radiol. 2007;30(1):6-25. http://dx.doi.org/10.1007/ s00270-006-0062-3.

182. Morse MA, Hanks BA, Suhocki $P$, et al. Improved time to progression for transarterial chemoembolization compared with transarterial embolization for patients with unresectable hepatocellular carcinoma. Clin Colorectal Cancer. 2012;11(3):185-190. http://dx.doi.org/10.1016/j.clcc.2011.11.003.

183. Bal CS, Kumar A. Radionuclide therapy for hepatocellular carcinoma: indication, cost and efficacy. Trop Gastroenterol. 2008;29(2):62-70.

184. Kumar A, Srivastava DN, Chau TTM, et al. Inoperable hepatocellular carcinoma: transarterial 188Re HDD-labeled iodized oil for treatment-prospective multicenter clinical trial. Radiology. 2007;243(2):509-519. http://dx.doi.org/10.1148/radiol. 2432051246 .

185. Lewandowski RJ, Kulik LM, Riaz A, et al. A comparative analysis of transarterial downstaging for hepatocellular carcinoma: chemoembolization versus radioembolization. $A m$ J Transplant. 2009;9(8):1920-1928. http://dx.doi.org/10.1111/j.16006143.2009.02695.x.

186. Salem R, Lewandowski RJ, Mulcahy MF, et al. Radioembolization for hepatocellular carcinoma using Yttrium-90 microspheres: a comprehensive report of long-term outcomes. Gastroenterology. 2010;138(1):52-64. http://dx.doi.org/10.1053/j.gastro. 2009.09.006.

187. Llovet JM, Ricci S, Mazzaferro V, et al. Sorafenib in advanced hepatocellular carcinoma. N Engl J Med. 2008;359(4):378-390. http://dx.doi.org/10.1056/NEJMoa0708857.

188. Cheng A-L, Kang Y-K, Chen Z, et al. Efficacy and safety of sorafenib in patients in the Asia-Pacific region with advanced hepatocellular carcinoma: a phase III randomised, double-blind, placebo- controlled trial. Lancet Oncol. 2009;10(1):25-34. http://dx.doi. org/10.1016/S1470-2045(08)70285-7.

189. Lencioni R, Kudo M, Ye S-L, et al. First interim analysis of the GIDEON (Global Investigation of therapeutic decisions in hepatocellular carcinoma and of its treatment with sorafenib) noninterventional study. Int J Clin Pract. 2012;66(7):675-683. http://dx.doi.org/10.1111/j.1742-1241.2012.02940.x.

190. Verslype C, Rosmorduc O, Rougier P. Hepatocellular carcinoma: ESMO-ESDO Clinical Practice Guidelines for diagnosis, treatment and follow-up. Ann Oncol. 2012;23(suppl 7):vii41-48. http://dx. doi.org/10.1093/annonc/mds225.

191. Bruix J, Sherman M. Management of hepatocellular carcinoma: an update. Hepatology. 2011;53(3):1020-1022. http://dx.doi. org/10.1002/hep.24199.

192. Parikh PM, Fuloria J, Babu G, et al. A phase II study of gemcitabine and cisplatin in patients with advanced hepatocellular carcinoma. Trop Gastroenterol. 2005;26(3):115-118.

193. Pande SB, Doval DC, Pavithran K, Sharma JB, Shirali R, Jena A. Gemcitabine and cisplatin-based combination chemotherapy in advanced hepatocellular carcinoma: an Indian experience. Indian J Med Paediatr Oncol. 2012;33(1):42-47. http://dx.doi.org/10. 4103/0971-5851.96968.

194. Sarin SK, Kumar M, Garg S, Hissar S, Pandey C, Sharma BC. High dose vitamin $\mathrm{K} 3$ infusion in advanced hepatocellular carcinoma. J Gastroenterol Hepatol. 2006;21(9):1478-1482. http://dx.doi. org/10.1111/j.1440-1746.2006.04383.x.

195. Schwarz RE, Abou-Alfa GK, Geschwind JF, Krishnan S, Salem R, Venook AP. Nonoperative therapies for combined modality treatment of hepatocellular cancer: expert consensus statement. HPB (Oxford). 2010;12(5):313-320. http://dx.doi.org/10. 1111/j.1477-2574.2010.00183.x.

196. Krishnan S, Dawson LA, Seong J, et al. Radiotherapy for hepatocellular carcinoma: an overview. Ann Surg Oncol. 2008;15(4):1015-1024. http://dx.doi.org/10.1245/s10434007-9729-5.

197. Hawkins MA, Dawson LA. Radiation therapy for hepatocellular carcinoma: from palliation to cure. Cancer. 2006;106(8):16531663. http://dx.doi.org/10.1002/cncr.21811.

198. Dhir V, Swaroop VS, Mohandas KM, et al. Combination chemotherapy and radiation for palliation of hepatocellular carcinoma. Am J Clin Oncol. 1992;15(4):304-307.

199. Therasse P, Arbuck SG, Eisenhauer EA, et al. New guidelines to evaluate the response to treatment in solid tumors. European Organization for Research and Treatment of Cancer, National Cancer Institute of the United States, National Cancer Institute of Canada. J Natl Cancer Inst. 2000;92(3):205-216.

200. Lencioni R, Llovet JM. Modified RECIST (mRECIST) assessment for hepatocellular carcinoma. Semin Liver Dis. 2010;30(1):5260. http://dx.doi.org/10.1055/s-0030-1247132.

201. Zimmerman MA, Ghobrial RM, Tong MJ, et al. Recurrence of hepatocellular carcinoma following liver transplantation: a review of preoperative and postoperative prognostic indicators. Arch Surg. 2008;143(2):182-188. http://dx.doi.org/10.1001/archsurg.2007.39. discussion 188 .

202. Hollebecque A, Decaens T, Boleslawski E, et al. Natural history and therapeutic management of recurrent hepatocellular carcinoma after liver transplantation. Gastroenterol Clin Biol. 2009;33(5):361-369. http://dx.doi.org/10.1016/j.gcb.2009. 02.036.

203. Roberts JP. Tumor surveillance-what can and should be done? Screening for recurrence of hepatocellular carcinoma after liver transplantation. Liver Transpl. 2005;11(suppl 2):S45-S46. http://dx.doi.org/10.1002/It.20605.

204. Chan SL, Chan ATC, Yeo W. Role of alpha-fetoprotein in hepatocellular carcinoma: prognostication, treatment monitoring or both? 
Future Oncol. 2009;5(6):889-899. http://dx.doi.org/10.2217/ fon.09.64.

205. Bertino G, Neri S, Bruno CM, et al. Diagnostic and prognostic value of alpha-fetoprotein, des- $\gamma$-carboxy prothrombin and squamous cell carcinoma antigen immunoglobulin $\mathrm{M}$ complexes in hepatocellular carcinoma. Minerva Med. 2011;102(5):363-371.

206. Sturgeon CM, Duffy MJ, Hofmann BR, et al. National Academy of Clinical Biochemistry Laboratory Medicine Practice Guidelines for use of tumor markers in liver, bladder, cervical, and gastric cancers. Clin Chem. 2010;56(6):e1-48. http://dx.doi.org/10. 1373/clinchem.2009.133124.

207. Induru RR, Lagman RL. Managing cancer pain: frequently asked questions. Cleve Clin J Med. 2011;78(7):449-464. http://dx. doi.org/10.3949/ccjm.78a.10054.

208. Koyyalagunta D, Bruera E, Solanki DR, et al. A systematic review of randomized trials on the effectiveness of opioids for cancer pain. Pain Physician. 2012;15(3 suppl I):ES39-58.

209. Habermehl D, Haase K, Rieken S, Debus J, Combs SE. Defining the role of palliative radiotherapy in bone metastasis from primary liver cancer: an analysis of survival and treatment efficacy. Tumori. 2011;97(5):609-613. http://dx.doi.org/10.1700/989. 10720.

210. Kim JY, Kay CS, Kim YS, et al. Helical tomotherapy for simultaneous multitarget radiotherapy for pulmonary metastasis. Int $J$ Radiat Oncol Biol Phys. 2009;75(3):703-710. http://dx.doi.org/ 10.1016/j.jijrobp.2008.11.065.

211. Kim K, Chie EK, Kim W, et al. Absence of symptom and intact liver function are positive prognosticators for patients undergoing radiotherapy for lymph node metastasis from hepatocellular carcinoma. Int J Radiat Oncol Biol Phys. 2010;78(3):729-734. http:/ / dx.doi.org/10.1016/j.jirobp.2009.08.047.

212. Hsu W-C, Tsai AC, Chan S-C, Wang P-M, Chung N-N. Mini-nutritional assessment predicts functional status and quality of life of patients with hepatocellular carcinoma in Taiwan. Nutr Cancer. 2012;64(4):543-549. http://dx.doi.org/10.1080/01635581. 2012.675620.

213. Koretz RL, Avenell A, Lipman TO. Nutritional support for liver disease. Cochrane Database Syst Rev. 2012;5:CD008344. http:// dx.doi.org/10.1002/14651858.CD008344.pub2.
214. Breitbart W, Rosenfeld B, Pessin H, et al. Depression, hopelessness, and desire for hastened death in terminally ill patients with cancer. JAMA. 2000;284(22):2907-2911.

215. Block SD, Billings JA. Patient requests to hasten death. Evaluation and management in terminal care. Arch Intern Med. 1994;154(18):2039-2047.

216. Srivastava DN, Gandhi D, Julka PK, Tandon RK. Gastrointestinal hemorrhage in hepatocellular carcinoma: management with transheptic arterioembolization. Abdom Imaging. 2000;25(4): 380-384.

217. Zhu Q, Li J, Yan J-J, Huang L, Wu M-C, Yan Y-Q. Predictors and clinical outcomes for spontaneous rupture of hepatocellular carcinoma. World J Gastroenterol. 2012;18(48):7302-7307. http:// dx.doi.org/10.3748/wjg.v18.i48.7302.

218. Lai ECH, Lau WY. Spontaneous rupture of hepatocellular carcinoma: a systematic review. Arch Surg. 2006;141(2):191-198. http://dx.doi.org/10.1001/archsurg.141.2.191.

219. Gopalakrishnan R, Sundaram J, Sattu K, Pandi A, Thiruvengadam D. Dietary supplementation of silymarin is associated with decreased cell proliferation, increased apoptosis, and activation of detoxification system in hepatocellular carcinoma. Mol Cell Biochem. 2013 May;377(1-2):163-176. http://dx.doi. org/10.1007/s11010-013-1582-1.

220. Thakur S, Singla A, Chawla Y, Rajwanshi A, Kalra N, Arora SK Expansion of peripheral and intratumoral regulatory T-cells in hepatocellular carcinoma: a case-control study. Indian J Pathol Microbiol. 2011;54(3):448-453. http://dx.doi.org/10.4103/ 0377-4929.85073.

221. Amarapurkar AD, Vibhav, Kim V. Angiogenesis in liver cirrhosis and hepatocellular carcinoma. Indian J Pathol Microbiol. 2008;51(3):323-328.

222. Rasheed Z, Ahmad R, Rasheed N, Ali R. Reactive oxygen species damaged human serum albumin in patients with hepatocellular carcinoma. J Exp Clin Cancer Res. 2007;26(3):395-404.

223. Khan AA, Jabeen M, Khan AA, Owais M. Anticancer efficacy of a novel propofol-linoleic acid-loaded escheriosomal formulation against murine hepatocellular carcinoma. Nanomedicine (Lond). 2013 Aug;8(8):1281-1294. http://dx.doi.org/10.2217/nnm. 12.166. 